\title{
Volatility Analysis and Visualization of Climate Data Based on Wavelets
}

\author{
Meili Liu ${ }^{1}$, Liwei Wang ${ }^{2}$, Chun-Te Lee ${ }^{2} \&$ Jeng-Eng Lin ${ }^{3}$ \\ ${ }^{1}$ Institute of Artificial Intelligence and Research Center, Midea Group, Shenzhen, China \\ ${ }^{2}$ Department of Mathematics, College of Science and Technology, Wenzhou-Kean University, Wenzhou, China \\ ${ }^{3}$ Department of Mathematical Sciences, George Mason University, USA \\ Correspondence: Chun-Te Lee, Department of Mathematics, College of Science and Technology, Wenzhou-Kean Univer- \\ sity, Wenzhou, China
}

Received: April 20, 2021 Accepted: June 1, 2021 Online Published: July 12, 2021

doi:10.5539/jmr.v13n4p50 URL: https://doi.org/10.5539/jmr.v13n4p50

\begin{abstract}
In this article, we analyze the real meteorological data recorded by Wenzhou Meteorological Bureau from 1951 to 1997. The data has not been used elsewhere and is available at Meteorological Station Wenzhou (ID: CHM00058659) at https://geographic.org/global_weather/china. We perform the time series volatility analysis including ARMA, ARIMA, ARCH-LM, PARCH, SARMA and Morlet wavelet analysis and use the Mann-Kendall (M-K) test to analyze both the trend and mutation defined by statistics sequence. In addition, a Morete wavelet time-frequency model is established to show that both the precipitation and temperature have a very important 12-month cycle and the precipitation is also very unstable. We then employ the STL, coif1 decompositions and NAR model to capture both the volatility and Heteroscedasticity in the data. In addition, the performance of the fitted model has been proven to be satisfactory on actual climate data with the small Mean Square Error (MSE), Root-Mean-Squarred Error (RMSE), and coefficient of determination. Finally, monthly average temperature is added as an exogenous (covariate) variable and a nonlinear autoregressive exogenous model is employed to improve the performance of the model. Our results show that the performance of NARX model is more accurate and stable with better mean square error.
\end{abstract}

Keywords: ARMA, ARIMA, meteorology, ARCH-LM, PARCH, SARMA

\section{Introduction}

Climate change is an important environmental, social and economic issue. It threatens the achievement of Millennium development goals aimed at poverty and hunger reduction, health improvement and environmental sustainability. A large number of studies have been conducted on several aspects to address the impact of climate change. Rosenzweig and Parry (Rosenzweig \& Pary, 1994) provides a global assessment of climate change on food supply and predict grain yield losses in several countries. (Barrios, Quattara \& Strolbl, 2008) recommend using the regression analysis to estimate the impact of weather changes on agriculture in some sub-Saharan African countries.

One of the important factors to measure climate change is to observe changes in temperature and precipitation in a specific area. In the past few decades, different research groups have released different global and hemispheric temperature estimates based on existing observational data. Significant improvements in information recovery and processing analysis techniques have led to longer temperature records based on more accurate estimates and better uncertainty assessments (Hansen et. al., 2010). Due to their importance, many forecast models for weather forecasting have been developed. Time series analysis has a wide range of applications in engineering, economics, meteorology, finance and many other fields. A number of stochastic time series models such as the Markov, Box-Jenkins (BJ) Seasonal Autoregressive Integrated Moving Average (SARIMA), deseaonalized Autoregressive Moving Average (DARMA), Periodic Autoregressive (PAR), Transfer Function Noise (TFN) and Periodic Transfer Function Noise (PTFN), are in use of these purposes (Ediger \& Akar, 2007). In recent years, a review work related to the detection and attribution of climate change based on time series techniques is presented (Estrada \& Perron, 2014) and the authors used co-integration techniques to solve the problem and addressed the point that time series can be better described as the stationary fluctuations of the trend function with the slope. In addition, some univariate time series models that deal with only one time series, including the autoregressive integrated moving average (ARIMA) model and its derivatives such as seasonal ARIMA (SARIMA), periodic ARIMA, and deseasonalized ARIMA models, have long been applied in monthly streamflow forecasting (Bender \& Simonovic, 1994). 
Greenhouse gas emissions lead to climate change, not only affecting temperature changes in an area, but also rainfall and snowfall in that area. Under the greenhouse effect, precipitation, temperature and weather patterns in an area may change or become more extreme. In (Trenberth, 2011), the authors addressed a direct influence of global warming on precipitation suggesting that increased heating leads to greater evaporation and thus surface drying, and thereby increasing the intensity and duration of drought. In (Brock \& Xepapadeas, 2021), the authors examined model projections of climate change from the Intergovernmental Panel on Climate Change Fourth Assessment Report and identifies regions where the largest climate changes are projected under high-end warming. The report in (Boudiaf et. al., 2020) studied the temperature and precipitation risk assessment under climate change effect in Northeast Algeria and confirms that climate change will continue to have an impact on temperature and precipitation of the region. In addition, an analysis of meteorological variables applying the modeling Ion-Wavelets in a hypothetical manner is carried out using the Morelet wavelet transform and shown in (Ramos-Aguilar et. al., 2013). Recently, (Hegerl et. al., 2019) addressed the causes of observed climate variations across the industrial period from 1750 to present and found that the observed pattern of precipitation response to warming from meteorology station data supports simulated changes and predictions of climate model.

Although weather and meteorological issues are changeable and unpredictable, the data types still indicate that they are time series patterns. This paper analyzes the meteorological data of Wenzhou in East China from January 1951 to December 1997 including the monthly precipitation $(\mathrm{mm})$, monthly maximum temperature $\left({ }^{\circ} \mathrm{F}\right)$, monthly minimum temperature $\left({ }^{\circ} \mathrm{F}\right)$, and monthly average temperature $\left({ }^{\circ} \mathrm{F}\right)$ ). The data is from Meteorological Station Wenzhou (ID: CHM00058659), China and is available in https://geographic.org/global_weather/china/wenzhou_659.html

The features of variable and their interpretations are illustrated in Table 1 1 . Note that there are total of 564 observations recorded and some missing data are found in PRCP, TAVG, TMAX amd TMIN. Given that the ratio of missing data to the total observations is small, so we choose to utilize the Catmull-Rom Spline method to smooth and fit the missing data.

The summary of basic statistics as well as numerical attributes of each variable are shown in Table 2 , where the mean, median, min, and max are self-explanatory variables. Figs. 1 12 show the time series of featuring variables, namely PRCP, TAVG, TMAX and TMIN, in the scale of Month. Here one can see that the fluctuations of PRCP are less cyclical than that of other variables. However, the volatility is stronger compared with other variables, indicating the nature of time series of precipitation. Notice that the trend of time series of TAVG, Tmax and Tmin are basically similar, and all of the characteristic variables appeared in obvious annual cycles. In other words, the PRCP fluctuates around 5, while TAVG, TMAX and TMIN are relatively maintained at a certain temperature level of $65^{\circ} \mathrm{F}$ in the scale of year.

In Fig. 3 it is seen that the PRCP started to increase slowly from January, and data numbers reach the peak both in June and August and decrease in the other months, showing a shape of zigzag. It can also be observed that TAVG, TMIN and TMAX have a similar trend in the time series, and the overall change is slow. In addition, the temperature began to rise slowly in January, peaked in July and August, and then decreased slowly in the next few months until it reaches the lowest point in January and February.

In order to make the comparisons of featuring variables of TAVG and PRCP in time series analysis, we select the top 10 years of values in July and last 10 years of values in January from TAVG, while for PRCP, we select the June data of the past 10 years and the January data of the last 10 years to facilitate the model processing. The results are shown in Fig. 4.

Fig. 4 shows that the highest temperature in July occurred in 1988, and the lowest temperature in January occurred in 1963. In addition, it also shows that the maximum precipitation occurred in June of 1990 and the minimum precipitation in occurred in January of 1963. It is noted that both the minimum temperature and precipitation occurred in January of 1963, and the ten highest temperatures in July in history include 1963, pointing out that extreme weather occurred in 1963.

The scatter plots in Fig. 5 shows that TAVG, TMIN, TMAX are all highly linear correlated, which confirmed the results obtained in the Figs. 11 2 Here Fig. 5 also gives us the idea to choose TAVG variable to represent the temperature to avoid the Pseudo-regression.

\section{Periodicity Analysis}

Periodicity occurs naturally in many environmental time series, such as hourly tide levels, daily stream flows, monthly average temperatures, and carbon dioxide exchange by growing plants. This section will focus on the examples of monthly precipitation and monthly average temperature in a demonstration of methods for analyzing periodically correlated time series together with the use of the Mann- Kendall (M-K) test and Morelet wavelet analysis.

\subsection{Mann-Kendall Test}

It is seen from previous sections that the time series of year trend of PRCP is fluctuating, therefore it is essential to rule out the Mutations of the series. In order to examine the mutational points, the Mann- Kendall (M-K) test is carried out on the 
time series data. The M-K method is a nonparametric statistical test method and is also known as a No-Distribution test. This method does not need to set the data distribution characteristics in advance, and is not interfered by some missing values and outliers. Therefore it is suitable for trend test and mutation points of meteorological data and hydrological time series (Yue, Pilon \& Cavadias, 2002). In addition, M-K test can be used to analyze both the trend and mutation of the time series by defining statistics values of UF and UB. Here the UF is defined as

$$
U F_{k}=\frac{\left[S_{k}-E\left(S_{k}\right)\right]}{\sqrt{\operatorname{Var}\left(S_{k}\right)}}, \quad k=1,2, \ldots, n,
$$

where

$$
S_{k}=\sum_{i=1}^{k} \sum_{j}^{i-1} \alpha_{i j}, \quad k=2,3, \ldots, n,
$$

and

$$
\alpha_{i j}=\left\{\begin{array}{ll}
1, & X_{i}>X_{j}, \\
0, & X_{i}<X_{j},
\end{array}, 1 \leq j \leq i .\right.
$$

On the other hand, the UB is defined as

$$
\left\{\begin{array}{c}
\mathrm{UB}_{k}=-\mathrm{UF}_{k} \\
k=n+1-k
\end{array}, k=1,2,3, \ldots, n .\right.
$$

By analyzing the statistical sequence of UF and UB, the trend and change of time series can be analyzed, and the time and area of mutation points can be identified. If UB $>0$, the time series is indicating an upward trend, while if $U F<0$, the time series indicates a downward trend over time. When it comes to exceeding the critical line, the data numbers indicate either a significant upward or downward trend. If both the time series curves of UF and UB have intersection points and the intersection point is between the critical lines, then the intersection point is the time when the mutation begins. The results of testing the time series curves of UF and UB are shown in Fig. 6. It can be seen in Fig. 6 that both the statistic values of UF and UB are developed within two critical line, which means there are no mutations between 1951-1997.

\subsection{Monthly/Yearly Periodicity Analysis Based on Morlet Wavelet}

It can be seen from the Figs. 1 12 that both the PRCP and TAVG have significantly Monthly period characteristics from 1951 to 1997. However, in the "year" scale, it can be seen that the period characteristics are not as important as the "month" scale, especially during this period, the TAVG remains almost unchanged. In order to quantitatively detect the periodic nature of data, the wavelet time-frequency (Morlet wavelet) method is employed to process and analyze the time series data. The Morlet wavelet is a continuous plane wave (Torrence \& Compo, 1998) modulated by Gauss function based on the following function:

$$
\Psi(t)=e^{i c t}\left(\mathrm{e}^{-\frac{t^{2}}{2}}-\sqrt{2} \mathrm{e}^{-\frac{c^{2}}{4}} \mathrm{e}^{-t^{2}}\right)
$$

The formula of discrete wavelet transform is expressed as:

$$
W_{f}(a, b)=|a|^{-\frac{1}{2}} \sum_{i=1}^{N} f(i \delta t) \psi^{*}\left(\frac{i \delta t-b}{a},\right)
$$

where $*$ denotes the complex conjugate, $a$ is a scale factor related to period and frequency, $b$ is translation factor of time position, $i$ is the time position label of data series, and $f(t)$ is the variable of time series. In addition, $W_{f}(a, b)$ is a wavelet coefficient and $\delta t$ is the difference of time series. The wavelet power spectrum is defined as follows:

$$
E_{a, b}=\left|W_{f}(a, b)\right|^{2}
$$

The total wavelet power spectrum $E_{a}$ represents the energy density corresponding to different scales a, which is defined as

$$
E_{a}=\frac{1}{N} \sum_{b=1}^{N}\left|W_{f}(a, b)\right|^{2} .
$$

In addition, it is found that the significant test of wavelet power spectrum is quite vital, which could be used to test the standard spectrum of red noise or white noise. The test process follows the patter: calculate the effective degree of freedom of wavelet power spectrum distribution, carry out the significance test of $\chi^{2}$ distribution. As such, the theoretical 
power spectrum $P$ of red noise or white noise will be calculated accordingly. If the total wavelet power spectrum $\left(E_{a}\right)$ is larger than the theoretical spectrum, the test is shown to be significantly credible. Here the theoretical power spectrum is defined as:

$$
P=\frac{\sigma^{2} P a \chi_{v}^{2}}{v}
$$

where $\chi_{v}^{2}$ is the value of $\chi^{2}$ with degree of freedom $v$, and $\sigma^{2}$ is the variance of time series which is defined by

$$
\sigma^{2}=\frac{1}{N} \sum_{i=1}^{N}\left(x_{i}-\bar{x}\right)^{2}
$$

Then the theoretical spectrum could be calculated by the following formula:

$$
P a=\frac{1-\alpha^{2}}{1+\alpha^{2}-2 \alpha \cos \left(\frac{2 \pi \delta t}{1.033 a}\right)}
$$

where $\alpha$ is the the Autocorrelation coefficient of lag 1 of series. if $E_{a}>P_{a}$, then it shows that the period corresponding to the total wavelet power spectrum is significant. To reduce side effects, the original time series was extended by 10 values from both sides.

Figs. 7 . 8 shows the monthly average precipitation in Wenzhou, eastern China from 1951 to 1997 , which contains several periodic variations in different scales, forming oscillation centers between positive and negative scales with obvious interannual variations. It is observed that there are mainly three distinct periodic changing times in the process, namely the 12 months, 30-50 months and 80-120 months. However, from the analysis of wavelet power spectrum (Fig. 7 , right color bar), it is found that only the 12-month period time change passes the noise test (see Fig. 7, red dotted line). From the time series of 12-month (one-year) analysis, it is found that the monthly precipitation periodic oscillation in Wenzhou area is very significant, and there are obvious clustering oscillations appeared in the whole time domain. It can also be seen that there are five clustering oscillations, namely 1951-1955; 1959-1963, 1968-1972, 1976-1980, and 1985-1989, appeared in the model which can be confirmed in Fig. 8. The clustering oscillation is manifested as the clustering oscillation of Real Part. In addition, we can know from the wavelet power spectrum that the wavelet power values in the early (1951-1961) and late (1986-1991) periods are larger than those in the middle (1962-1985). Notice that there are two peaks in the year of 1986 and 1991, which indicate that the 12-month cycle changing time of precipitation in these two specific years is very significant.

Figs. 9. 10 show the average monthly temperature in Wenzhou from 1951 to 1997, which contains almost only one scale of periodic change (about 12 months) and notice that its wavelet power spectrum passed the noise test (red dotted line is red noise spectrum).The annual cycle oscillation of monthly temperatures in Wenzhou area is very significant throughout the whole time domain. The results in Fig. 10 show that there are similar periodic changes in the entire time domain, which shows that the annual periodic change of monthly average temperature is more significant than that of monthly average precipitation, and the interference is small.

\section{Volatility Analysis On PRCP}

The understanding of volatility is a key concept for analyzing environmental data. This is of greater importance for climate data because it provides key aspects such as the return on precipitation and temperature of weather conditions and helps with effective analysis. The unpredictable nature of volatility causes heteroskedasticity which leads to difficulty in modelling. Consequently, time series models are desirable to predict volatility. An illustration of the same has been shown through an example of fitting time series models on the volatility of a listing from the the Stock Exchange. This paper attempts to employ different methods to analyze the volatility phenomenon. Based on the results shown in Fig. 8 it is seen that the spectrum is not significantly zero besides the sole peak. It is also observed that there is a flat peak between $80-100$ months and the spectrum remains at a non-zero level, which means that although PRCP fails to pass the red noise test, it still has a certain degree of volatility. Those volatility might play a vital role in dominating the regularity or uncertainty of precipitation in wenzhou. Therefore, it is necessary to analyze it in this article. The flow chart of research process is demonstrated in Fig. 11

The remainder of the time series is extracted based on Seasonal and Trend decomposition using Loess (STL) procedure. In order to capture the volatility in remainder analysis, the technique of wavelet decomposition is employed to decompose the time series into low-frequency and high-frequency terms of d1, d2, d3, d4 and d5 through the method of wavelet decomposition and reconstruction. The time series models ARMA, SARMA-PARCH, SARMA-EGARCH, and NAR are established according to their respective characteristics. Finally, we fit the values linearly and combine the values to obtain 
the final fitting of $\mathrm{R}$ series.

\subsection{STL Decomposition}

STL stands for Seasonal and Trend decomposition using Loess. This is a statistical method of decomposing a Time series data into three components containing seasonality, trend and residual, whereas seasonality is a regular and predictable pattern that recur at a fixed interval of time.

In order to analyse the volatility of PRCP, some certain factors should be ruled out. Given that there is 12-months periodic phenomenon in PRCP, we use STL procedure to process data. Based on STL procedure (Robert, William \& Irma, 1990), PRCP data will be decomposed into three parts, namely seasonal, trend and remainder. The PRCP data can be represented as follows:

$$
P R C P_{t}=S_{t}+T_{t}+R_{t},
$$

where $S_{t}$ and $T_{t}$ are terms meaning certainty, and the term $R_{t}$ is the remainder due to the fact that there might contain some vital information about the volatility. Based on the previous analysis and monthly data of precipitation and temperature, we set the periodicity to 12 and smooth the windows of seasons, trends and filters. These are the default functions in the software EVIEWS, and the results in seasonal and diagnostics panels are shown in Figs. 12,13, suggesting that seasonal component is around 12 months and the trend component has no significantly upward or downward trend. Flat lines in each of months indicate that the choice of 12 months as the periodicity and parameters for seasonal window is appropriate.

\subsection{Coifl Wavelet Decomposition}

It is well known that the wavelet analysis method has a strong multi-resolution ability. It can separate the high frequency (representing the period and disturbance part) and the low frequency (representing the trend part) of the precipitation sequence, and process the PRCP sequence from different levels according to the characteristics of each sub-sequence. In this section, we resort to the coif 1 wavelet analysis. The results of decomposition together with residuals of reconstruction are shown in Figs. 12 13 In addition, Figs. 14 15 illustrate the coif1 wavelet decomposition of PRCP data and Fig. 15 shows that the residual is about $10^{-11}$ order, which indicates the reconstruction is efficient.

\subsection{Models}

In this section, different models are selected for variables a5, d1, d2, d5 from Table 7 10 . First, the ARMA model requires the property of sequence stationarity. In general, time series data are prone to non-stationary problems which can lead to the destruction of the consistency of large sample statistics and produce pseudo regression problem. Before the follow-up test, the stationarity of each variable is tested by the augmented Dickey-Fuller test (Dickey \& Fuller, 1979), which is used to test the null hypothesis that a unit root is present in an autoregressive model. The test results are shown in Table 3 Here $\mathrm{D}(*)$ denotes the first-order difference, and $[\mathrm{C}, \mathrm{T}, \mathrm{L}]$ is the basic type of unit root, which represents constant term, trend term and lag order term respectively. The probabilities in [**] represent one-side p-values suggested by Mackinnon (1996). In addition, results shows that six variables are stationary at 5\% level. The lags of ARMA /SARMA model are selected based on minimum AIC. The procedure of model selection and its criteria based on AIC and dependent variables a5, d1, d2, and d5 can be seen in Table 7 7 10 It is the selection of parameters of ARMA(p,q) based on AIC, SC and HQ criteria. In addition, some variance equations are added in order to capture the volatility and conditional variance. If the residual has shown to exist in Heteroscedasticity, it means that it is possible to establish models to fit the data in the sense of Heteroscedasticity. In general, heteroscedasticity of residuals could be tested based on ARCH-LM model by setting a optimal lags operator, and the choice of the best lag factor varies by methods. In (Chong, Ahmad \& Abdullah, 1999), the authors use ARCH-LM(12) to reject the null hypothesis and concluded that a very high-order ARCH model is needed to model the heteroscedasticity. In (Engle, 1982), it is shown that the Lagrange multiplier test for a first-order linear ARCH effect is not significant. However, testing for a fourth-order linear ARCH process and the chi-squared statistic with 4 degrees of freedom will be highly significant. In (Engle, 2001), authors choose one lag in order to incorporate the ARCH effect. Given that the ARCH-LM testing might be sensitive to the choice of lags which means different lags could give different results and the auto-correlation in most series dies out after 15 lags, we choose the number of lags 1,5,10,15 for research, and choose the best lag according to the AIC, SC and HQ criteria. We choose the lag with the smallest number of AIC, SC, HQ to judge heteroscedasticity.

In addition, the ARCH model family is considered an effective way to solve our problems. There are lots of research results addressing the heteroscendasticity problem of the data. In (Zhou \& Li, 2018), the authors use the Generalized Auto-Regressive Conditional Heteroskedasticity $(\mathrm{GARCH})$ model to analyze the carbon price fluctuation characteristics. In (Amiri, 2014), the authors analyze the conditional variance of a function of ACDC level known as ACDC level growth rate (ACDCGR) using the generalised autoregressive conditional heteroskedasticity (GARCH) and GARCH models with leverage effect. In addition, research results in (Liu \& Shi, 2013) show that SARMA-GARCH,ARMAGARCH, ARMAEGARCH-M models can be used to deal with different volatility problems, which shows the efficiency and effectiveness 
of ARCH model family. In this article, through the time-testing and selections based on the criteria information, residual diagnostic and stability of model, we utilize the PARCH and EGARCH as variance equations to capture the volatility for variables $\mathrm{d} 1, \mathrm{~d} 2$, and $\mathrm{d} 5$. The variance equation of $\operatorname{PARCH}(\mathrm{p}, \mathrm{q})$ is expressed as follows:

$$
\sigma_{t}^{\delta}=\omega+\sum_{j=1}^{q} \beta_{j} \sigma_{t-j}^{\delta}+\sum_{i=1}^{p} \alpha_{i}\left(\left|\varepsilon_{t-i}\right|-\gamma_{i} \varepsilon_{t-i}\right)^{\delta},
$$

where $\delta>0,\left|\gamma_{i}\right| \leq 1$ for $i=1, \ldots, r$, with $\gamma_{i}=0$ for all $i>r$, and $r \leq p$. Moreover, the variance equation of EGARCH(p,q) is:

$$
\operatorname{Ln} \sigma_{t}^{2}=\alpha+\sum_{j=1}^{p} \gamma_{j}\left|\frac{\varepsilon_{t-j}}{\sigma_{t-j}}\right|+\sum_{j=1}^{p} \rho_{j} \frac{\varepsilon_{t-j}}{\sigma_{t-j}}+\sum_{j=1}^{p} \beta_{i} \ln \left(\sigma_{t-i}^{2}\right) .
$$

Notice that the EGARCH model first relaxed the non negative constraints on the parameters of the GARCH model, and then adds an asymmetric term

$$
\sum_{j=1}^{p} \rho_{j} \frac{\varepsilon_{t-j}}{\sigma_{t-j}}
$$

to represent the leverage effect. In our approach, the ARMA model is employed for a5 due to the fact that there is no heteroskedasticity in the residual analysis. However, as for $\mathrm{d} 3$ and $\mathrm{d} 4$, we find that there are no suitable SARMA and ARCH models for our data analysis. The main problem is that most models can not pass the residual white noise test. It is believed that the model parameters $\mathrm{d} 3, \mathrm{~d} 4$ could be highly complex and non-linear. Therefore, nonlinear autoregressive (NAR) based on neural networks will be one of our methods to process the data in the following sections. In this study, the calculated mean square error $M S E$ and the coefficient of determination $R^{2}$ are used to compare the performance of the model.

$$
\text { MSE }=\frac{1}{n} \sum_{i=1}^{n}\left(y_{i}-\hat{y}_{i}\right)^{2}, R^{2}=1-\frac{\sum_{i=1}^{n}\left(y_{i}-\hat{y}_{i}\right)^{2}}{\sum_{i=1}^{n}\left(y_{i}-\bar{y}\right)^{2}},
$$

where $n$ is the number of data points, $y_{i}$ is observed values, $\hat{y_{i}}$ is predicted values, and $\bar{y}$ is mean of data $y$.

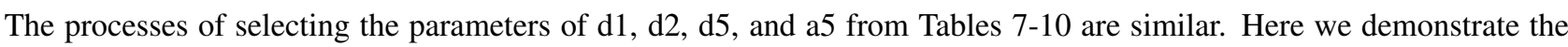
selection of $\mathrm{d} 1$ as an example. Firstly, the mean equation is selected based on AIC (see Tables 7. 10), and from that we choose ARMA $(1,2)$ to process the data. In what follows, the ARCH-LM test is employed for testing the Heteroscedasticity. The results are shown in Table 4 , which shows that the null hypothesis is rejected in all lags. Based on AIC, SC, $\mathrm{HQ}$, we choose lag 10 from the table to be the optimal lag with $\mathrm{P}$ value set to 0 , indicating that there is Heteroscedasticity in residuals $\left(\epsilon_{t}^{d 1}\right)$. Then the squared-residuals-autocorrelation is tested and results are shown in Fig. 16 The results suggest that the squared residuals shows autocorrelation of up to lag 15, indicating that it is not white noise and a suitable model can be established to extract the information. It also indicates that Heteroscedasticity model could be built using the residuals $\left(\epsilon_{t}^{d 1}\right)$. Through times of testing and selection based on criteria information, residual diagnostic and stability of the model, we finally choose $\operatorname{ARMA}(1,2)-\operatorname{PARCH}(2,1)$ as a good candidate model to perform the data. Its equation is expressed as

$$
\begin{array}{r}
(1+0.7 L) d 1_{t}=\left(1-0.35 L-0.64 L^{2}\right) \epsilon_{t}^{d 1} \\
\left(\sigma_{t}^{d 1}\right)^{2}=0.75+0.23\left(\sigma_{t-1}^{d 1}\right)^{2}+0.59\left(\left|\epsilon_{t-1}^{d 1}\right|-0.06 \epsilon_{t-1}^{d 1}\right)^{2}-0.22\left|\epsilon_{t-1}^{d 1}\right|^{2},
\end{array}
$$

where $L$ is the lag operator and the upper index $d 1$ stands for the variable name. The parameter estimations for variables $\mathrm{d} 1, \mathrm{~d} 2, \mathrm{~d} 3, \mathrm{~d} 4$ and $\mathrm{d} 5$ shown in Tables 11 14 demonstrate that the parameters in mean equations are all significant, while the parameters in variance equation are significant apart from $\gamma_{1}$. It also indicates that there is no significant Leverage effect. Table 5 shows the results of ARCH-LM test after building the PARCH model. Based on the optimal information criteria (AIC, SC and HQ), lag1 is selected by the model and p value is 0.8498 , which indicates that there is no Heteroskedasticity in the residual. The residuals autocorrelation diagrams in Figs. 23 28 suggests that there is no residuals autocorrelation at 5\% level. It is suggesting that the model is effective and can be used to fit the data well. The fitting results and conditional variance diagram are shown in Fig. 17] where the red dot line is standard error based on variance equation. The variance diagram shows that uncertainty volatility of $\mathrm{d} 1$ is the greatest in data source No. 1974-MO1 and smallest in data source No.1961M07-1969M12.

In a similar fashion, the SARMA(5,5)(1,0)-EARCH(1,1) models can be established for $\mathrm{d} 2$ with the following resulting 
equations:

$$
\begin{gathered}
\left(1-0.33 L+0.91 L^{2}-0.11 L^{3}+0.26 L^{4}+0.04 L^{5}\right)\left(1-0.14 L^{12}\right) d 2_{t}= \\
0.0000478+\left(1+0.29 L-0.66 L^{2}-0.18^{3}-0.22 L^{4}-0.29 L^{5}\right) \epsilon_{t}^{d 2} \\
\left.\ln \left[\left(\sigma_{t}^{d 2}\right)^{2}\right]=-0.82+0.95\left|\frac{\epsilon_{t-1}^{d 2}}{\sigma_{t-1}^{d-1}}\right|-0.14 \frac{\epsilon_{t-1}^{d 2}}{\sigma_{t-1}^{d 2}}+0.74 \ln \left[\left(\sigma_{t-1}^{d 2}\right)^{2}\right)^{2}\right]
\end{gathered}
$$

In a similar fashion, the SARMA(3,4)(1,1)-PARCH(1,1) model can be established for $\mathrm{d} 5$ with the resulting equations as:

$$
\begin{gathered}
\left(1-0.84 L-0.19 L^{2}+0.1 L^{3}\right)\left(1-0.39 L^{48}\right) d 5_{t}= \\
\left(1+0.7 L+0.28 L^{2}+0.21 L^{3}+0.03 L^{4}\right)\left(1+0.15 L^{48}\right) \epsilon_{t}^{d 5} \\
\left(\sigma_{t}^{d 5}\right)^{0.28}=0.07+0.62\left(\left|\epsilon_{t-1}^{d 5}\right|+0.06 \epsilon_{t-1}^{d 5}\right)^{0.28}+0.25\left(\sigma_{t-1}^{d 5}\right)^{0.28}
\end{gathered}
$$

To proceed, the ARMA $(4,4)$ model can be established for a5, and the resulting equations are:

$$
\begin{gathered}
\left(1-1.88 L+1.59 L^{2}-1.42 L^{3}+0.72 L^{4}\right) a 5_{t}= \\
0.81+\left(1-0.16 L+0.54 L^{2}-0.18 L^{3}-0.46 L^{4}\right) \epsilon_{t}^{a 5} .
\end{gathered}
$$

Notice that the NAR model can be established for $\mathrm{d} 3, \mathrm{~d} 4$ in a similar fashion. The model could be implemented by neural network. Therefore we create a two layers with 15 hidden neurons and set the numbers of delay to be 12 based on previous periodicity analysis. The NAR network was trained using the Bayesian Regularization algorithm and results are shown in Figs. 18 19, suggesting that the model performance is efficient. For NAR-d3 model, the MSE is $1.5667 * 10^{4}$ and $R^{2}$ is 1 in test set. The $M S E$ is 0.0307 and $R^{2}$ is 0.9911 in test set. For NAR-d4, the $M S E$ is $8.9672 * 10^{4}$ and $R^{2}$ is 0.9995 in test set. The MSE is 0.0129 and $R^{2}$ is 0.9895 in test set. The high value of $R^{2}$ indicates the NAR serves as a model with good performance for $\mathrm{d} 3$, $\mathrm{d} 4$. In addition, both $\mathrm{d} 3$, $\mathrm{d} 4$ can not reject the null hypothesis of ARCH-LM test at lag1 with optimal Information criteria, namely, $\mathrm{AIC}=-2.718678, \mathrm{SC}=-2.702761, \mathrm{HQ}=-2.712452$ and $\mathrm{AIC}=-4.650315$, $\mathrm{SC}=-4.634398, \mathrm{HQ}=-4.644090$ respectively. It indicates that the squared is of homoscedasticity (see Fig. 20) and the residuals autocorrelation graphs in Figs. 23.28 also show the residuals are white noise and the information has been fully extracted. Notice that the total fitted remainder $\hat{R}_{t}$ of the model can be represented as linear combination of all sub-series as follows:

$$
\hat{R}_{t}=a \hat{5}_{t}+d \hat{1}_{t}+d \hat{2}_{t}+d \hat{3}_{t}+d \hat{4}_{t}+d \hat{5}_{t} .
$$

Here we set the fitted series $\hat{R}_{t}$ from the real Data Source: No.1955M04-1997M12 due to the fact that the lags in some ARMA models may cause some missing data before 1955MO4. Consequently, the result shows that MSE is 2.5008 and RMSE is $1.5814, R^{2}=0.8057$, which indicates that $80 \%$ of the changes in volatility can be interpreted by model.

\subsection{Covariates and NARX Model}

In order to compare and improve the model that can accurately fit the volatility, we consider the feature variable of TAVG as exogenous variable and put it into our models for test. In view of the obvious periodicity of TAVG, it cannot be regarded as a strictly stationary sequence. Therefore, it is not suitable to use the ARIMA model. In general, this is not a fixed sequence and the use of ARIMA model requires that each sequence is stable, otherwise there will be a problem of estimation in parameters. As a result, we proposed using a nonlinear autoregressive exogenous (NARX) neural network model to convert the input into two neurons so that TAVG can be added in the model. The NARX can be described by the following non-linear function:

$$
y(t)=f(x(t-1), \ldots, x(t-d), y(t-1), \ldots, y(t-d)),
$$

where $x(t-d)$ is an exogenous variable, and $d$ is the time delays which can be used to determine the effectiveness of NARX. In time series modeling, a nonlinear autoregressive exogenous model (NARX) is a nonlinear autoregressive model which has exogenous inputs. This means that the model relates the current value of a time series to both the past values of the same series and current and past values of the driving (exogenous) series- that is, of the externally determined series that influences the series of interest. The NARX model has a wide range of applications in multi-step neural network prediction and shows a good performance in dealing with some complex series that can not be fitted well by ARIMA. In (Abou Rjeily et. al., 2017), NARX was built to develop a flooding forecast system and showed a high efficiency in representing the real urban drainage systems response to a forecasted storm event in flooding forecast system. In (Guzman, Paz \& Tagert, 2017), the authors employed NARX to simulate daily groundwater levels at a local scale in the Mississippi River Valley Alluvial aquifer located in the southeastern United States. In (Wunsch, Liesch \& Broda, 2018), NARX 
was applied to obtain groundwater level forecasts for several wells in southwest Germany and showed an outstanding suitability in model prediction for groundwater level. In this section, we construct a NARX Neural network as shown in Fig. 21 and use the Bayesian Regularization algorithm The NARX network to train the proposed model. As a result, the optimal parameters including the number of hidden neurons and time delays are selected based on the performance of Residuals auto-correlations $M S E$ and $R^{2}$. Firstly, each variables such as $a \hat{5}_{t}, d \hat{1}_{t}, d \hat{2}_{t}, d \hat{3}_{t}, d \hat{4}_{t}, d \hat{5}_{t}$ are fitted by NARX model, and then calculates $\hat{R}_{t}$ by applying the equation in 21 . The results are illustrated in Table 6 It shows that the MSE is 0.5219 , which is smaller than the model case without exogenous variables (MSE=2.5008). In addition, it also shows that $R^{2}$ is 0.9195 , accounting for nearly $92 \%$ of the change in volatility explained by the model. The result of fitted data from a new model is shown in Fig. 22 In our view point, the result of modified model with $R^{2}=0.9195$ is better than previous model without exogenous variable $\left(R^{2}=0.8057\right)$.

\section{Conclusion}

We investigate the characteristics of cyclical and variables of climate change based on the real datasets of monthly precipitation and temperature recorded in East China Wenzhou meteorological station. It is found that both the precipitation and temperatures have the nature of one-year periodicity, which matches common sense of monthly data. We also find that temperature in Wenzhou of East China appears to be more stable compared with the precipitation from the Morlet wavelet analysis. It also shows that precipitation contains other non-zero frequencies except 12-month period. Furthermore, we proceed to study the volatility of precipitation by extracting the remainders of the data from certainty terms based on STL decomposition, and employ the coif1 wavelet to decompose the remainder into 5 levels in order to capture and fit the volatility. In addition, our results show that the proposed model has strong ability to capture heteroscedasticity of time series data. As the series has the phenomenon of "volatility cluster", it shows that the variance changes with time which is inconsistent with the assumption of homoscedasticity of traditional ARMA method. Furthermore, by considering the disturbance of the variance of time series $R_{t}$, we introduce both the PARCHand and EGARCH models in our analysis and both are shown to be good at describing the variance of precipitation time series as well as strengthen the control of square difference volatility practically. Finally, the NAR model is employed for $\mathrm{d} 3$, d4, which, in general, could not be fitted by general linear models, and it turns out that we obtain good results of fitted data of $\hat{R}_{t}$. However, the coefficient $R^{2}$ is not large enough, and it can be considered that this problem may be caused by some parameters in mean equation, which are not important for improving the efficiency of the model. Data analysis of temperature and precipitation in East China provides us with information about climate change in East China. From our point of view, this research has brought many new insights into the analysis of real data on climate change and global warming issues from weather stations. We believe that establishing a more advanced and more effective time series model to predict regional temperature and precipitation under extreme climatic conditions is the subject of future climate change research.

\section{Acknowledgements}

The authors would like to thank the anonymous reviewers and editors for their valuable comments and suggestions to improve the quality of this paper.

\section{References}

Abou, R. Y., Abbas, O., Sadek, M., Shahrour, I., \& Hage, C. F. (2017). Flood forecasting within urban drainage systems using NARX neural network. Water Science and Technology, 76(9), 2401-2412. https://doi.org/10.2166/wst.2017.409

Amiri, E. (2014). Empirical study of GARCH models with leverage effect in an environmental application. Environmental and ecological statistics, 2l(1), 125-141. https://doi.org/10.1007/s10651-013-0248-1

Barrios, S., \& Quattara, B., \& Strolbl, E. (2008). The impact of climate change on agriculture production: is it different for Africa? Food Policy, 33, 287-298. https://doi.org/10.1016/j.foodpol.2008.01.003

Bender, M., \& Simonovic, S. (1994). Time-series modeling for long-range stream-flow forecasting. Journal of Water Resources Planning and Management, 120(6), 857-870. https://doi.org/10.1061/(ASCE)0733-9496(1994)120:6(857)

Boudiaf, B., Dabanli, I., Boutaghane, H., \& Şen, Z. (2020). Temperature and precipitation risk assessment under climate change effect in northeast Algeria. Earth Systems and Environment, 1-14. https://oi.org/10.1007/s41748-01900136-7

Brock, W., \& Xepapadeas, A. (2021). Regional climate policy under deep uncertainty: robust control and distributional concerns. Environment and Development Economics, 26(3), 211-238. https://doi.org/10.1017/S1355770X20000248

Chong, C. W., Ahmad, M. I., \& Abdullah, M. Y. (1999). Performance of GARCH models in forecasting stock market volatility. Journal of forecasting, 18(5), 333-343. https://doi.org/10.1002/(SICI)1099-131X(199909)18:5;333::AIDFOR742;3.0.CO;2-K 
Dickey, D. A., \& Fuller, W. A. (1979). Distribution of the estimators for autoregressive time series with a unit root. Journal of the American statistical association, 74(366a), 427-431. https://doi.org/10.1080/01621459.1979.10482531

Ediger, V. Ş., \& Akar, S. (2007). ARIMA forecasting of primary energy demand by fuel in Turkey. Energy policy, 35(3), 1701-1708. https://doi.org/10.1016/j.enpol.2006.05.009

Engle, R. (2001). GARCH 101: The use of ARCH/GARCH models in applied econometrics. Journal of economic perspectives, 15(4), 157-168. https://doi.org/10.1257/jep.15.4.157

Engle, R. F. (1982). Autoregressive conditional heteroscedasticity with estimates of the variance of United Kingdom inflation. Econometrica: Journal of the econometric society, 987-1007. https://doi.org/10.2307/1912773

Estrada, F., \& Perron, P. (2014). Detection and attribution of climate change through econometric methods. Boletín de la Sociedad Matemática Mexicana, 20(1), 107-136. https://doi.org/10.1007/s40590-014-0009-7

Guzman, S. M., Paz, J. O., \& Tagert, M. L. M. (2017). The use of NARX neural networks to forecast daily groundwater levels. Water resources management, 31(5), 1591-1603. https://doi.org/10.1007/s11269-017-1598-5

Hansen, J., Ruedy, R., Sato, M.,\& Lo, K. (2010). Global surface temperature change. Reviews of Geophysics, 48(4). https://doi.org/10.1029/2010RG000345

Hegerl, G. C., Brnnimann, S., Cowan, T., Friedman, A. R., Hawkins, E., Iles, C., ... \& Undorf, S. (2019). Causes of climate change over the historical record. Environmental Research Letters, 14(12). https://doi.org/10.1088/17489326/ab4557

Liu, H., \& Shi, J. (2013). Applying ARMA-GARCH approaches to forecasting short-term electricity prices. Energy Economics, 37, 152-166. https://doi.org/10.1016/j.eneco.2013.02.006

Ramos-Aguilar, R., Máximo-Romero, P., Soto-Cruz, B. S., Alcántara-Iniesta, S., \& Pé rez-Luna, J. G. (2013). Analysis of the meteorological variables for Puebla City 2011-2012 applying the modeling Ion-Wavelets in a hypothetical manner. Atmospheric and climate sciences, 450-458. https://doi.org/10.4236/acs.2013.34046

Robert, C., William, C., \& Irma, T. (1990). STL: A seasonal-trend decomposition procedure based on loess. Journal of official statistics, 6(1), 3-73. https://www.bibsonomy.org/bibtex/24bf4893a61f6e30b2dbf7f37884295ed/jwbowers

Rosenzweig, C., \& Pary, M. L. (1994) Potential impacts of climate change on world food supply. Nature, 367, 133-138. https://doi.org/10.1038/367133a0

Torrence, C., \& Compo, G. P. (1998). A practical guide to wavelet analysis. Bulletin of the American Meteorological society, 79(1), 61-78. https://doi.org/10.1175/1520-0477(1998)079;0061:APGTWA

Trenberth, K. E. (2011). Changes in precipitation with climate change. Climate Research, 47(1-2), 123-138. https://doi.org/10.3354/cr00953

Wunsch, A., Liesch, T., \& Broda, S. (2018). Forecasting groundwater levels using nonlinear autoregressive networks with exogenous input (NARX). Journal of hydrology, 567, 743-758. https://doi.org/10.1016/j.jhydrol.2018.01.045

Yue, S., Pilon, P., \& Cavadias, G. (2002). Power of the Mann-Kendall and Spearman's rho tests for detecting monotonic trends in hydrological series. Journal of hydrology, 259(1-4), 254-271. https://doi.org/10.1016/S0022-1694(01)005947

Zhou, K., \& Li, Y. (2018). An empirical analysis of carbon emission price in China. Energy Procedia, 152, 823-828. https://doi.org/10.1016/j.egypro.2018.09.196 
Table 1. Interpretation of variables in raw data

\begin{tabular}{|l|l|}
\hline Variables & Interpretation \\
\hline PRCP & Monthly precipatation $(\mathrm{mm})$ \\
\hline TAVG & Monthly average temperature $\left({ }^{\circ} \mathrm{F}\right)$ \\
\hline TMAX & Monthly maximum temperature $\left({ }^{\circ} \mathrm{F}\right)$ \\
\hline TMIN & Monthly maximum temperature $\left({ }^{\circ} \mathrm{F}\right)$ \\
\hline
\end{tabular}

Table 2. Basic statistics and numerical attributes of variables

\begin{tabular}{|l|l|l|l|l|}
\hline & TMIN & TMAX & TAVG & PRCP \\
\hline Mean & 58.82380 & 71.68768 & 65.25056 & 5.630897 \\
\hline Median & 59.15000 & 72.50000 & 66.50000 & 4.535000 \\
\hline Maximum & 79.10000 & 94.40000 & 86.70000 & 25.89000 \\
\hline Minimum & 31.40000 & 45.30000 & 41.00000 & 0.020000 \\
\hline Std. Dev. & 13.23973 & 12.84772 & 13.00572 & 4.484944 \\
\hline Skewness & -0.048910 & -0.067747 & -0.050632 & 1.339785 \\
\hline Kurtosis & 1.626651 & 1.719119 & 1.649106 & 5.084307 \\
\hline Jarque-Bera & 44.54792 & 38.98687 & 43.12645 & 270.8242 \\
\hline Probability & 0.000000 & 0.000000 & 0.000000 & 0.000000 \\
\hline Sum & 33176.62 & 40431.85 & 36801.32 & 3175.826 \\
\hline Sum Sq. Dev. & 98688.59 & 92930.98 & 95230.77 & 11324.59 \\
\hline Observations & 564 & 564 & 564 & 564 \\
\hline
\end{tabular}

Table 3. Unit root test results

\begin{tabular}{|l|l|l|l|}
\hline Variables & ADF Statistics(C,T,L) & 5\% Level & Prob.** $^{* *}$ \\
\hline a5 & $-3.190372(\mathrm{C}, 0,9)$ & -2.866538 & 0.0211 \\
\hline d1 & $-12.69449(\mathrm{C}, 0,12)$ & -2.866576 & 0.0000 \\
\hline d2 & $-8.407512(0,0,18)$ & -1.941405 & 0.0000 \\
\hline d3 & $-11.17616(0,0,18)$ & -1.941405 & 0.0000 \\
\hline d4 & $-8.030578(0,0,17)$ & -1.941404 & 0.0000 \\
\hline d5 & $-7.878308(0,0,17)$ & -1.941404 & 0.0000 \\
\hline
\end{tabular}

Table 4. Heteroskedasticity Test (ARCH-LM)

\begin{tabular}{|l|l|l|l|l|l|}
\hline Lag & Prob. F & Prob. Chi-Square & AIC & SC & HQ \\
\hline 1 & 0.0256 & 0.0256 & 5.259518 & 5.274912 & 5.265528 \\
\hline 5 & 0.0000 & 0.0000 & 5.220303 & 5.266738 & 5.238436 \\
\hline $10^{*}$ & 0.0000 & 0.0000 & 5.202997 & 5.288717 & 5.236484 \\
\hline 15 & 0.0000 & 0.0000 & 5.213452 & 5.339007 & 5.262521 \\
\hline
\end{tabular}

Table 5. Heteroskedasticity Test (ARCH-LM) after modification

\begin{tabular}{|l|l|l|l|l|l|}
\hline Lag & Prob. F & Prob. Chi-Square & AIC & SC & HQ \\
\hline $1^{*}$ & 0.8501 & 0.8498 & 4.407410 & 4.422825 & 4.413428 \\
\hline 5 & 0.8142 & 0.8122 & 4.418700 & 4.465198 & 4.436859 \\
\hline 10 & 0.3562 & 0.3539 & 4.428008 & 4.513847 & 4.461545 \\
\hline 15 & 0.0920 & 0.0938 & 4.432408 & 4.558139 & 4.481549 \\
\hline
\end{tabular}


Table 6. Results Of NARX

\begin{tabular}{|l|l|l|l|l|l|l|l|}
\hline & $a \hat{5}_{t}$ & $d \hat{1}_{t}$ & $d \hat{2}_{t}$ & $d \hat{3}_{t}$ & $d \hat{4}_{t}$ & $d \hat{5}_{t}$ & $\hat{R}_{t}$ \\
\hline Hidden Neurons & 15 & 10 & 15 & 15 & 15 & 20 & - \\
\hline Time Delays & 12 & 4 & 10 & 12 & 8 & 12 & - \\
\hline$R^{2}$ & 0.9618 & 0.9256 & 0.8477 & 0.9734 & 0.9485 & 0.9120 & 0.9195 \\
\hline MSE & $8.585 \times 10^{-4}$ & 0.3759 & 0.5850 & 0.0494 & $4.263 \times 10^{-3}$ & $1.996 \times 10^{-3}$ & 0.5219 \\
\hline
\end{tabular}

Table 7. Model Selection Criteria Table Based On AIC. Dependent Variable: a5

\begin{tabular}{|c|c|c|c|}
\hline Model & AIC & Model & AIC \\
\hline$"(4,4)(0,0) "$ & -4.829671 & $"(1,4)(0,0) "$ & -4.714782 \\
\hline$"(4,2)(0,0) "$ & -4.795624 & $"(2,1)(0,0) "$ & -4.712859 \\
\hline$"(3,3)(0,0) "$ & -4.788925 & $"(3,0)(0,0) "$ & -4.709935 \\
\hline$"(3,4)(0,0) "$ & -4.787311 & $"(2,0)(0,0) "$ & -4.709179 \\
\hline "(4,3)(0,0)" & -4.786462 & $"(1,2)(0,0) "$ & -4.544123 \\
\hline " & -4.785518 & $"(1,1)(0,0) "$ & -4.493081 \\
\hline$"$ & -4.784871 & $"(1,0)(0,0) "$ & -3.941114 \\
\hline$"(4,1)(0,0) "$ & -4.779103 & $"(0,4)(0,0) "$ & -2.646888 \\
\hline$"(2,3)(0,0) "$ & -4.744725 & $"$ & -2.198271 \\
\hline$"$ & -4.742749 & $"(0,2)(0,0) "$ & -1.166548 \\
\hline$"$ & -4.740809 & $"(0,1)(0,0) "$ & -0.092089 \\
\hline "(4,0)(0,0)" & -4.73305 & $"(0,0)(0,0) "$ & 1.270036 \\
\hline$"(1,3)(0,0) "$ & -4.717234 & & \\
\hline
\end{tabular}

Table 8. Model Selection Criteria Table Based On AIC. Dependent Variable: d1

\begin{tabular}{|c|c|c|c|}
\hline Model & AIC & Model & AIC \\
\hline$"(1,2)(0,0) "$ & 3.122415 & $"(4,2)(0,0) "$ & 3.255434 \\
\hline$"(0,4)($ & 3.12619 & $"(2,1)(0$ & .325273 \\
\hline$"(2,2)($ & 3.127144 & $(5,2$ & 3.32804 \\
\hline$"(3,2)($ & 3.128756 & $"(5,4$ & 3.344997 \\
\hline$"(0,3)$ & 3.128896 & $"(1$, & 3.399736 \\
\hline$"(2,3)$ & 3.13075 & $"(4,4$ & 3.41618 \\
\hline$"(5,3)$ & 3.131338 & "(5,0 & 3.531119 \\
\hline$"(3,3)$ & 3.136763 & $"(0,1$ & 3.559202 \\
\hline$"(1,4)$ & 3.139455 & $"(3,4)$ & 3.559543 \\
\hline$"(4,3)$ & 3.141987 & $"(4,0)$ & 3.641274 \\
\hline$"(0,2)$ & 3.17642 & $"(3,0)$ & 3.718138 \\
\hline$"(1,3)(0$ & 3.180013 & $"(2,0)(0$, & 3.906724 \\
\hline$"(5,1)(0,0) "$ & 3.200012 & $"(2,4)(0$ & 4.009002 \\
\hline$"(4,1)(0,0) "$ & 3.234843 & $"(1,0)(0$ & 4.103905 \\
\hline$"(3,1)(0,0) "$ & 3.251766 & $"(0,0)(0,0) "$ & 4.566166 \\
\hline
\end{tabular}


Table 9. Model Selection Criteria Table Based On AIC. Dependent Variable: d2

\begin{tabular}{|c|c|c|c|c|c|}
\hline Model & AIC & Model & AIC & Model & AIC \\
\hline$"(5,5)(1,0) "$ & 1.550383 & $"(5,1)(0,0) "$ & 2.601519 & $"(3,4)(0,0) "$ & 1.997987 \\
\hline$"$ & 1.589557 & $"(4,1)(0,0) "$ & 2.603615 & $"(6,5)(1,0) "$ & 2.056065 \\
\hline$"(1,5)(1,0) "$ & 1.603242 & $"(2,2)(1,0) "$ & 2.619668 & $"(3,3)(1,0) "$ & 2.104399 \\
\hline$"(2,5)(1,0) "$ & 1.622261 & $"(3,2)(0,0) "$ & 2.629718 & $"(2,4)(1,0) "$ & 2.109018 \\
\hline$"(1,5)(0,0) "$ & 1.642646 & $"(4,4)(1,0) "$ & 2.631543 & $"(2,3)(1,0) "$ & 2.112158 \\
\hline$"(3,5)(0,0) "$ & 1.671191 & $"(6,1)(0,0) "$ & 2.689106 & $"(4,5)(1,0) "$ & 2.127938 \\
\hline " $(5,4)(1,0)$ & 1.673902 & "(4,3)(0,0)" & 2.75166 & "(2,3)(0,0)" & 2.140903 \\
\hline$"(5,4)(0,0) "$ & 1.690585 & $"(6,0)(1,0) "$ & 2.790651 & $"(6,2)(1,0) "$ & 2.181018 \\
\hline "(6,4)(1,0)" & 1.76857 & $"(6,0)(0,0) "$ & 2.847858 & $"(6,2)(0,0) "$ & 2.205251 \\
\hline$"(6,4)(0,0) "$ & 1.790483 & "(2,4)(0,0)" & 2.883661 & $"(5,2)(1,0) "$ & 2.22022 \\
\hline$"(6,3)(1,0) "$ & 1.796183 & $"(3,1)(1,0) "$ & 2.897981 & $"(1,4)(1,0) "$ & 2.235155 \\
\hline$"(0,5)(1,0) "$ & 1.8132 & $"(2,1)(1,0) "$ & 2.89827 & $"(4,5)(0,0) "$ & 2.254158 \\
\hline$"(6,3)(0,0) "$ & 1.848986 & $"(3,1)(0,0) "$ & 2.931782 & $"(1,4)(0,0) "$ & 2.272974 \\
\hline$"(3,5)(1,0) "$ & 1.852315 & $"(5,0)(1,0) "$ & 3.056278 & $"(4,2)(1,0) "$ & 2.354699 \\
\hline$"(0,5)(0,0) "$ & 1.855812 & $"(1,2)(1,0) "$ & 3.058062 & $"(6,1)(1,0) "$ & 2.355011 \\
\hline$"(5,3)(1,0) "$ & 1.908673 & $"(4,0)(1,0) "$ & 3.067506 & $"(5,2)(0,0) "$ & 2.364433 \\
\hline$"(4,3)(1,0) "$ & 1.913007 & $"(5,0)(0,0) "$ & 3.087083 & $"(0,3)(1,0) "$ & 2.387527 \\
\hline$"(5,3)(0,0) "$ & 1.944719 & "(1,2)(0,0)" & 3.095614 & $"(4,2)(0,0) "$ & 2.395899 \\
\hline$"(0,4)(0,0) "$ & 1.954403 & $"(4,0)(0,0) "$ & 3.10639 & $"(0,3)(0,0) "$ & 2.424885 \\
\hline "(3,4)(1,0)" & 1.969308 & "(0,2)(1,0)" & 3.253591 & $"(2,5)(0,0) "$ & 2.4357 \\
\hline$"(6,5)(0,0) "$ & 1.986163 & $"(0,2)(0,0) "$ & 3.289832 & $"(3,2)(1,0) "$ & 2.593321 \\
\hline$"(1,0)(1,0) "$ & 4.097986 & $"(4,4)(0,0) "$ & 4.411325 & $"(2,1)(0,0) "$ & 3.33137 \\
\hline$"(1,0)(0,0) "$ & 4.134965 & $"(0,4)(1,0) "$ & 4.713479 & $"(1,1)(1,0) "$ & 3.366482 \\
\hline$"(0,0)(1,0) "$ & 4.192235 & $"(2,2)(0,0) "$ & 2.494764 & $"(0,1)(1,0) "$ & 3.382259 \\
\hline "(0,0)(0,0)" & 4.228054 & $"(1,3)(1,0) "$ & 2.501227 & $"(1,1)(0,0) "$ & 3.404314 \\
\hline$"(3,3)(0,0) "$ & 2.551048 & $"(1,3)(0,0) "$ & 2.520611 & $"(0,1)(0,0) "$ & 3.419802 \\
\hline$"(4,1)(1,0) "$ & 2.580395 & $"(3,0)(0,0) "$ & 3.481479 & $"(3,0)(1,0) "$ & 3.44702 \\
\hline "(5,1)(1,0)" & 2.580603 & $"$ & 3.500113 & $"(2,0)(1,0) "$ & 3.467059 \\
\hline
\end{tabular}


Table 10. Model Selection Criteria Table Based On AIC. Dependent Variable: d5

\begin{tabular}{|c|c|c|c|c|c|}
\hline Model & AIC & Model & AIC & Model & AIC \\
\hline$"(3,4)(1,1) "$ & -2.540458 & $"(2,2)(0,0) "$ & -1.774572 & $"(3,2)(0,1) "$ & -2.206388 \\
\hline$"(3,2)(1,0) "$ & -2.500269 & $"(2,3)(0,0) "$ & -1.771268 & $"(4,1)(0,1) "$ & -2.201425 \\
\hline$"(3,2)(1,1) "$ & -2.498495 & $"(3,1)(0,0) "$ & -1.770965 & $"(4,3)(0,1) "$ & -2.174013 \\
\hline$"(2,4)(1,0) "$ & -2.497753 & $"(0,4)(1,0) "$ & -1.765015 & $"(3,1)(0,1) "$ & -2.162686 \\
\hline$"(2,4)(1,1) "$ & -2.497325 & $"(1,4)(0,0) "$ & -1.736139 & $"(4,2)(0,1) "$ & -2.159255 \\
\hline " $(4,3)(1,0)$ & -2.496269 & $"(4,2)(0,0) "$ & -1.712472 & $"(2,2)(0,1) "$ & -2.132801 \\
\hline$"(4,1)(1,0) "$ & -2.495834 & $"(1,3)(0,0) "$ & -1.710211 & $"(2,3)(0,1) "$ & -2.132169 \\
\hline$"(4,1)(1,1) "$ & -2.494148 & $"(4,0)(0,0) "$ & -1.708706 & $"(1,3)(0,1) "$ & -2.123505 \\
\hline "(3,3)(1,0)" & -2.474637 & "(2,1)(0,0)" & -1.68768 & $"(1,4)(0,1) "$ & -2.120032 \\
\hline$"$ & -2.47095 & $"$ & -1.683532 & $"(4,3)(0,0) "$ & -1.807655 \\
\hline$"(3,1)(1,0) "$ & -2.445231 & $"(2,0)(0,0) "$ & -1.681981 & $"(1,0)(1,0) "$ & -1.800597 \\
\hline$"(1,4)(1,0) "$ & -2.437992 & $"(1,2)(0,0) "$ & -1.571991 & $"(1,0)(1,1) "$ & -1.797536 \\
\hline "(4,4)(1,0)" & -2.436035 & $"(1,1)(0,0) "$ & -1.549916 & $"(4,1)(0,0) "$ & -1.797291 \\
\hline$"(1,4)(1,1)$ & -2.435598 & $"(1,0)(0,1) "$ & -1.492917 & $"(2,1)(0,1) "$ & -2.097785 \\
\hline$"(1,3)(1,1) "$ & -2.42416 & $"(0,4)(0,1) "$ & -1.486669 & $"(2,0)(0,1) "$ & -2.095547 \\
\hline "(2,3)(1,0)" & -2.420215 & $"(0,3)(1,0) "$ & -1.271842 & $"(3,0)(0,1) "$ & -2.095391 \\
\hline$"(2,2)(1,0) "$ & -2.419589 & $"(0,3)(1,1) "$ & -1.196299 & $"(2,4)(0,1) "$ & -2.029871 \\
\hline$"(4,4)(1,1) "$ & -2.419099 & $"(1,0)(0,0) "$ & -1.105281 & $"(1,2)(0,1) "$ & -1.98131 \\
\hline$"(2,3)(1,1) "$ & -2.418645 & $"(0,3)(0,1) "$ & -0.913031 & $"(1,1)(0,1) "$ & -1.953972 \\
\hline " & -2.417978 & $"$ & -0.816152 & $"(3,4)(0,0) "$ & -1.873331 \\
\hline " $(1,3)(1,0)$ & -2.415029 & " $(3,4)(1,0) "$ & -0.809424 & $"(4,2)(1,0) "$ & -1.841717 \\
\hline "(4,0)(1,0)" & -2.40288 & $"(4,3)(1,1) "$ & -0.7653 & $"(4,4)(0,0) "$ & -1.839524 \\
\hline$"(4,0)(1,1) "$ & -2.401795 & $"(0,2)(1,1) "$ & -0.640251 & $"(3,3)(0,0) "$ & -1.829721 \\
\hline$"(2,1)(1,0) "$ & -2.385093 & $"(0,2)(1,0) "$ & -0.607621 & $"(2,4)(0,0) "$ & -1.821654 \\
\hline " $(2,1)(1,1)$ & -2.384098 & $"(0,2)(0,1) "$ & -0.357674 & $"(3,2)(0,0) "$ & -1.808265 \\
\hline "'(3,3)(1,1)" & -2.383711 & $"$ & 0.201495 & $"(0,4)(1,1) "$ & -1.7876 \\
\hline "(2,0)(1,0)" & -2.383598 & $"(0,1)(1,1) "$ & 0.303596 & $"(0,1)(0,0) "$ & 0.711017 \\
\hline$"(3,0)(1,0) "$ & -2.38307 & $"(0,1)(1,0) "$ & 0.348662 & $"(0,4)(0,0) "$ & 0.747145 \\
\hline$"(2,0)(1,1) "$ & -2.382647 & "(4,2)(1,1)" & 0.4222 & $"(0,0)(1,1) "$ & 1.651321 \\
\hline$"(3,0)(1,1) "$ & -2.382099 & $"(0,1)(0,1) "$ & 0.558284 & $"(0,0)(1,0) "$ & 1.697881 \\
\hline " $(1,2)(1,0)$ & -2.277453 & "(1,1)(1,1)" & -2.252195 & $"(0,0)(0,1) "$ & 1.899262 \\
\hline$"(1,2)(1,1) "$ & -2.275707 & $"(3,4)(0,1) "$ & -2.25028 & $"(0,0)(0,0) "$ & 2.045519 \\
\hline ”(1,1)(1,0)" & -2.254323 & $"(4,4)(0,1) "$ & -2.232166 & ”(4,0)(0,1)" & -2.116209 \\
\hline "(3,3)(0,1)" & -2.207692 & & & & \\
\hline
\end{tabular}

Table 11. ARMA(1,2)-PARCH(2,1) For d1

\begin{tabular}{ccccc}
\hline \multicolumn{5}{c}{ Mean Equation } \\
\hline Variable & Coefficient & Std. Error & z-Statistic & Prob. \\
\hline AR(1) & -0.702620 & 0.090974 & -7.723273 & 0.0000 \\
MA(1) & -0.350527 & 0.103075 & -3.400694 & 0.0007 \\
MA(2) & -0.642191 & 0.106685 & -6.019493 & 0.0000 \\
\hline \multicolumn{5}{c}{ Variance Equation } \\
\hline$\omega$ & 0.751076 & 0.026563 & 28.27562 & 0.0000 \\
$\alpha_{1}$ & 0.589064 & 0.086321 & 6.824144 & 0.0000 \\
$\gamma_{1}$ & 0.060255 & 0.057961 & 1.039577 & 0.2985 \\
$\alpha_{2}$ & -0.218902 & 0.042267 & -5.179047 & 0.0000 \\
$\beta_{1}$ & 0.225948 & 0.044953 & 5.026333 & 0.0000 \\
$\delta$ & 1.955625 & 0.349289 & 5.598877 & 0.0000 \\
\hline
\end{tabular}


Table 12. ARMA(4,4) For a5

\begin{tabular}{crlrr}
\hline Variable & Coefficient & Std. Error & t-Statistic & Prob. \\
\hline C & 0.812333 & 0.134699 & 6.030706 & 0.0000 \\
AR(1) & 1.880464 & 0.040540 & 46.38485 & 0.0000 \\
AR(2) & -1.587739 & 0.073990 & -21.45890 & 0.0000 \\
AR(3) & 1.424522 & 0.070955 & 20.07651 & 0.0000 \\
AR(4) & -0.722062 & 0.033008 & -21.87561 & 0.0000 \\
MA(1) & -0.164461 & 0.221000 & -0.744167 & 0.4571 \\
MA(2) & 0.539923 & 0.143753 & 3.755901 & 0.0002 \\
MA(3) & -0.178569 & 0.416777 & -0.428452 & 0.6685 \\
MA(4) & -0.458393 & 1.641475 & -0.279257 & 0.7802 \\
\hline \hline
\end{tabular}

Table 13. SARMA(5,5)(1,0)-EARCH(1,1) For d2

\begin{tabular}{crrrr}
\hline \hline Variable & Coefficient & Std. Error & z-Statistic & Prob. \\
\hline $\mathrm{C}$ & $4.78 \mathrm{E}-05$ & $1.07 \mathrm{E}-05$ & 4.443660 & 0.0000 \\
$\mathrm{AR}(1)$ & 0.328151 & 0.000323 & 1016.999 & 0.0000 \\
$\mathrm{AR}(2)$ & -0.908665 & $4.74 \mathrm{E}-05$ & -19185.43 & 0.0000 \\
$\mathrm{AR}(3)$ & 0.107811 & 0.006290 & 17.13900 & 0.0000 \\
$\mathrm{AR}(4)$ & -0.262966 & 0.019618 & -13.40421 & 0.0000 \\
$\mathrm{AR}(5)$ & -0.043064 & 0.007298 & -5.900569 & 0.0000 \\
$\mathrm{SAR}(12)$ & 0.144116 & 0.014956 & 9.636301 & 0.0000 \\
$\mathrm{MA}(1)$ & 0.287446 & 0.002070 & 138.8654 & 0.0000 \\
$\mathrm{MA}(2)$ & -0.660850 & 0.000167 & -3968.107 & 0.0000 \\
$\mathrm{MA}(3)$ & -0.180111 & 0.000586 & -307.5195 & 0.0000 \\
$\mathrm{MA}(4)$ & -0.224765 & 0.001140 & -197.1882 & 0.0000 \\
$\mathrm{MA}(5)$ & -0.287533 & 0.002525 & -113.8683 & 0.0000 \\
\hline & \multicolumn{5}{|}{ Variance Equation } & \\
\hline$\alpha$ & -0.821953 & 0.096544 & -8.513778 & 0.0000 \\
$\gamma$ & 0.947284 & 0.137147 & 6.907060 & 0.0000 \\
$\rho$ & -0.138224 & 0.076695 & -1.802253 & 0.0715 \\
$\beta$ & 0.737632 & 0.051136 & 14.42498 & 0.0000 \\
\hline
\end{tabular}

Table 14. SARMA(3,4)(1,1)-PARCH(1,1) For d5

\begin{tabular}{crrrr}
\hline Variable & Coefficient & Std. Error & z-Statistic & Prob. \\
\hline \hline AR(1) & 0.843505 & 0.034135 & 24.71073 & 0.0000 \\
AR(2) & 0.189657 & 0.068394 & 2.773008 & 0.0056 \\
AR(3) & -0.096087 & 0.036883 & -2.605206 & 0.0092 \\
SAR(48) & 0.391482 & 0.005085 & 76.98375 & 0.0000 \\
MA(1) & 0.704440 & 0.044015 & 16.00442 & 0.0000 \\
MA(2) & 0.275469 & 0.015916 & 17.30815 & 0.0000 \\
MA(3) & 0.208496 & 0.003673 & 56.76489 & 0.0000 \\
MA(4) & 0.033370 & 0.003739 & 8.923812 & 0.0000 \\
SMA(48) & 0.152516 & 0.007164 & 21.28944 & 0.0000 \\
\hline \multicolumn{5}{c}{ Variance Equation } \\
\hline$\omega$ & 0.069491 & 0.036979 & 1.879200 & 0.0602 \\
$\alpha$ & 0.622648 & 0.078263 & 7.955862 & 0.0000 \\
$\gamma$ & -0.059106 & 0.043693 & -1.352758 & 0.1761 \\
$\beta$ & 0.252284 & 0.063772 & 3.956055 & 0.0001 \\
$\delta$ & 0.280012 & 0.132729 & 2.109656 & 0.0349 \\
\hline
\end{tabular}




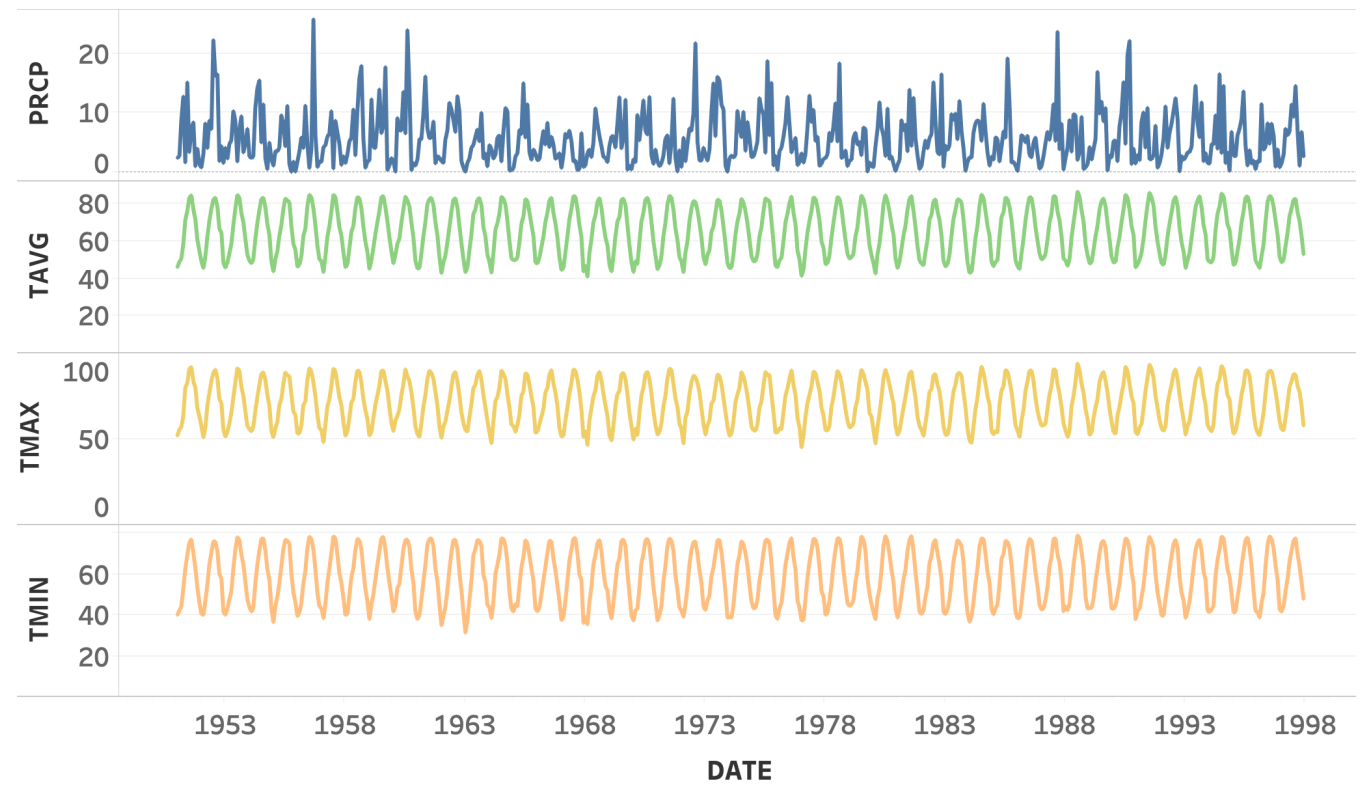

Figure 1. The Monthly Trend Of PRCP, TAVG, TMAX,TMIN

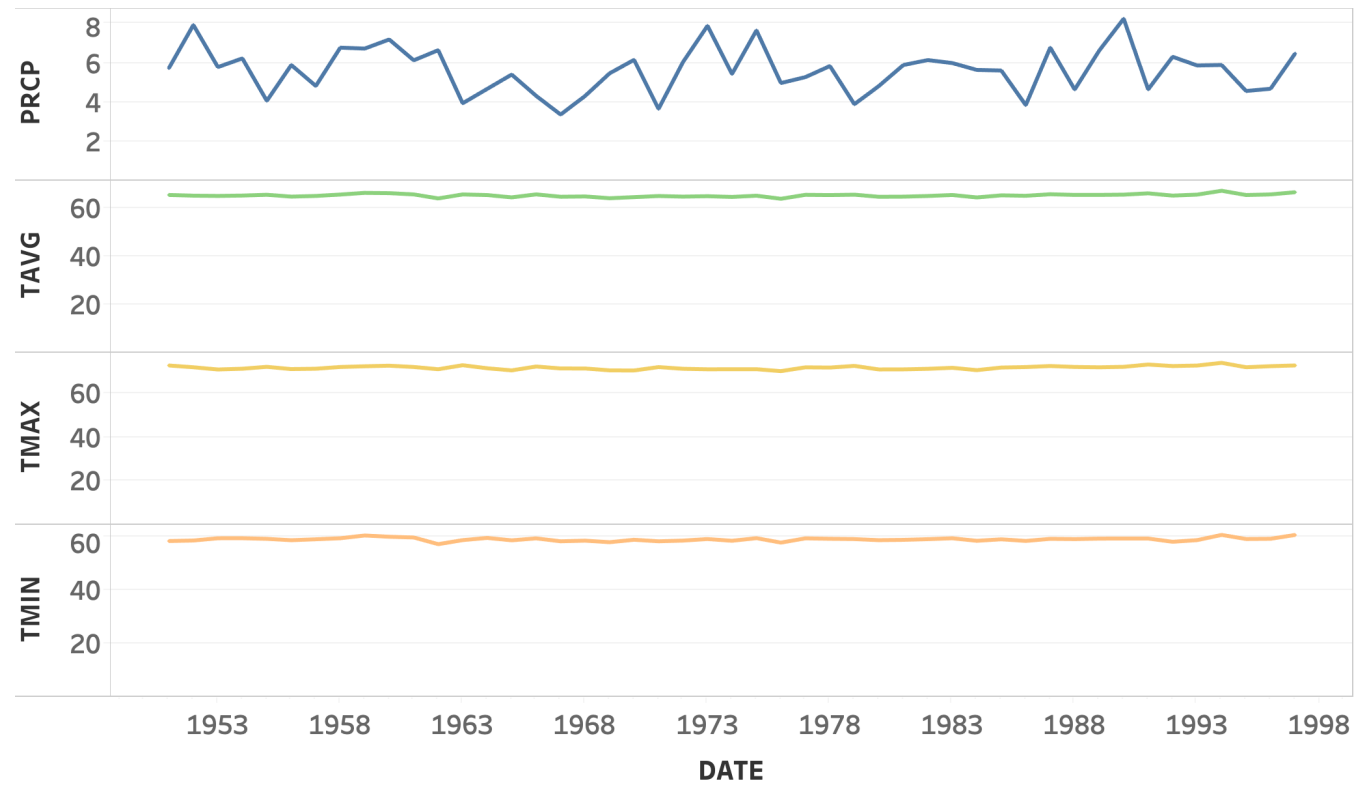

Figure 2. The Yearly Trend of PRCP, TAVG, TMAX,TMIN 


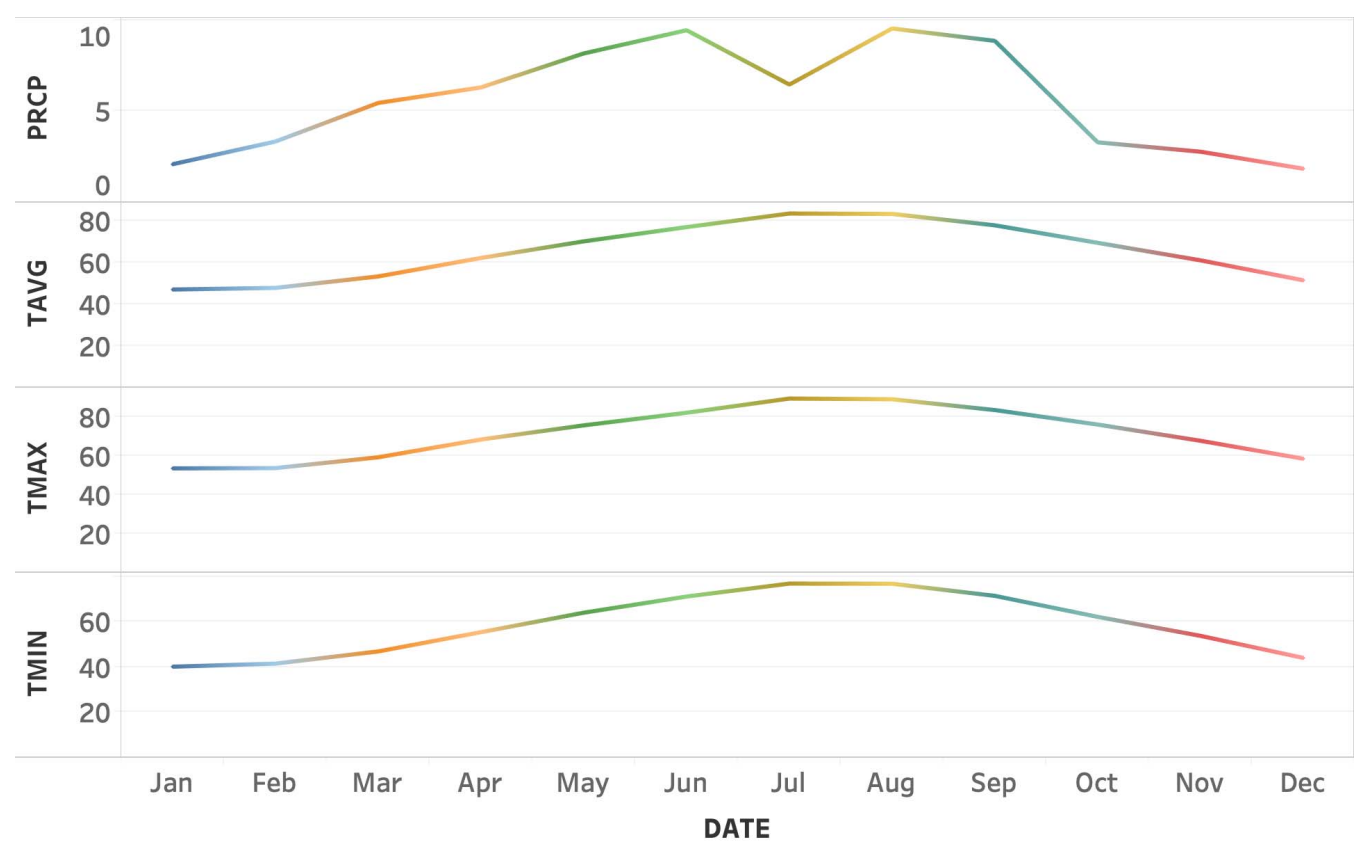

Figure 3. The Average Trend Of PRCP,TAVG,TMAX,TMIN Within A Year
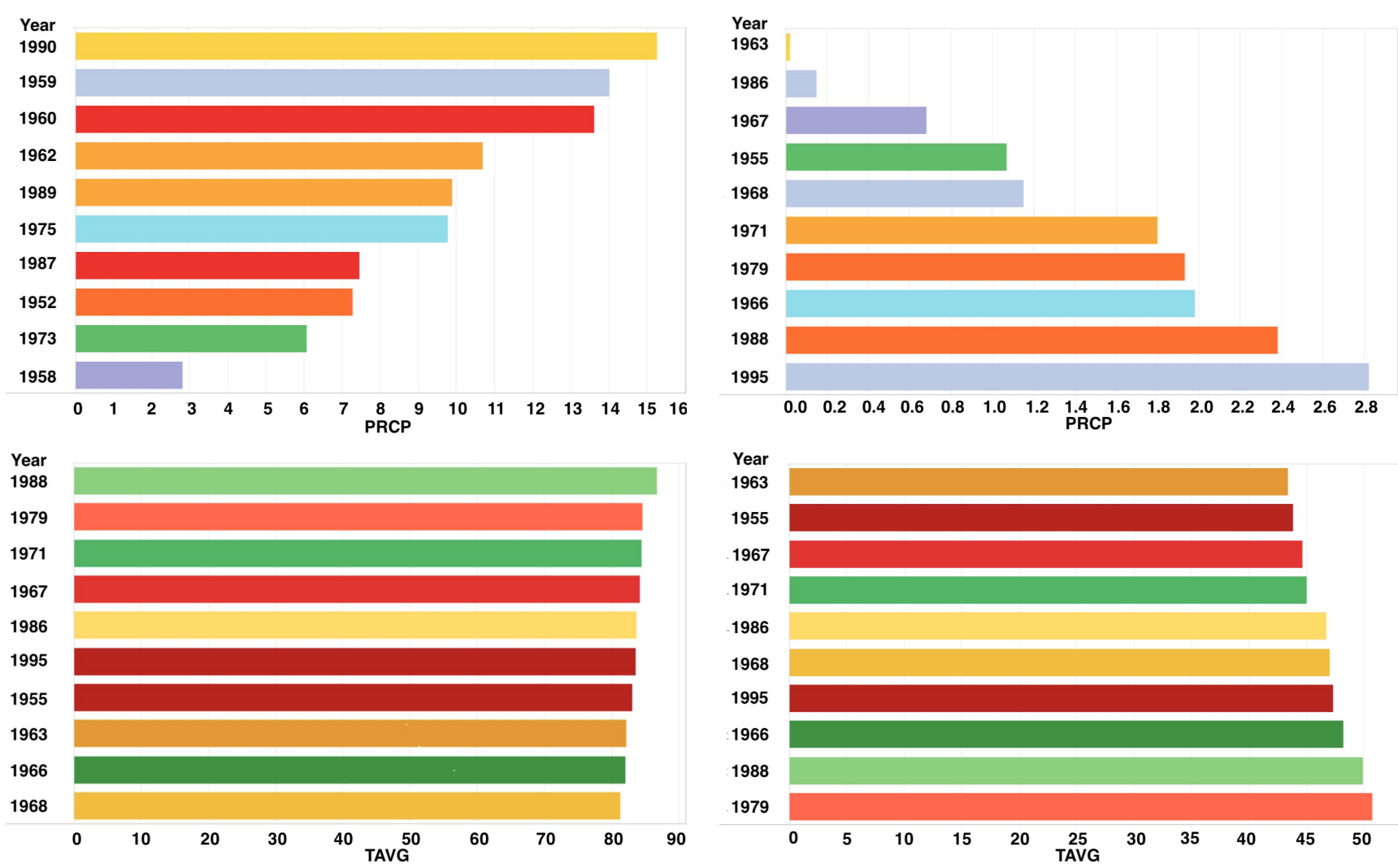

Figure 4. (a) Average of PRCP for each Year broken down by Month. Color shows details about Year. The view is filtered on Month(June) and Year(Top10 based on PRCP). (b) Average of PRCP for each Year broken down by Month. Color shows details about Year. The view is filtered on Month(January) and Year(Bottom10) based on PRCP). (c) TAVG for each Year broken down by Month. Color shows details about Year. The view is filtered on Month(July) and Year(top

10) based on TAVG. (d) TAVG for each Year broken down by Month. Color shows details about Year. The view is filtered on Month(January) and Year(bottom 10) based on TAVG 


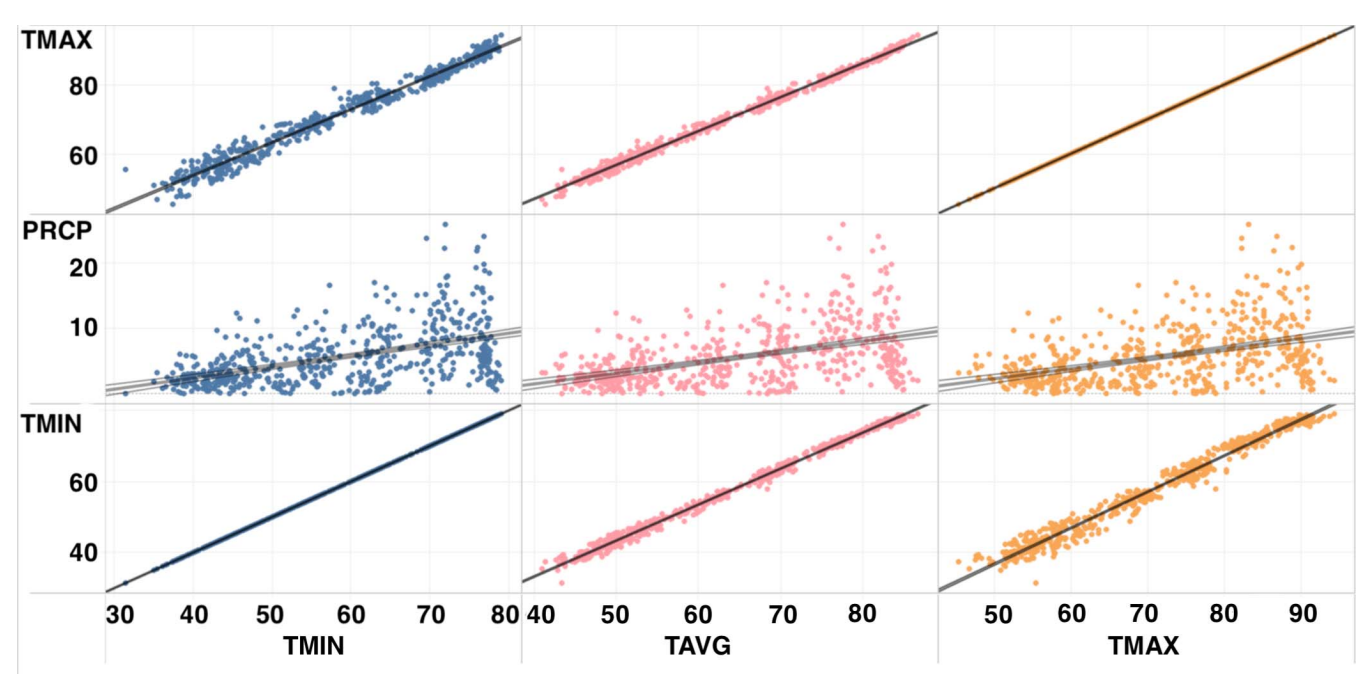

Figure 5. Linear Regression Among All Variables

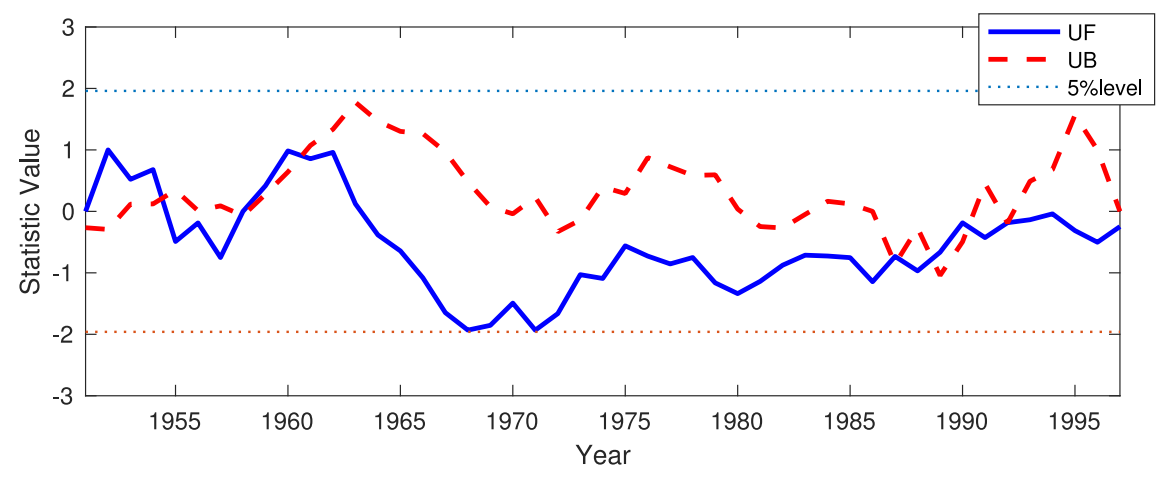

Figure 6. Result of the M-K Test

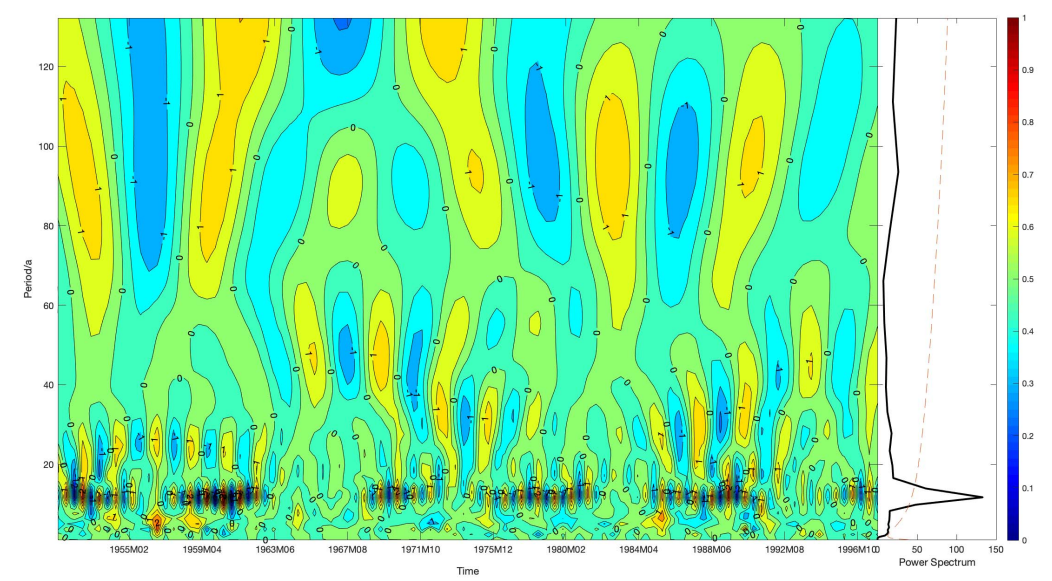

Figure 7. PRCP Real part contour map of Morlet wavelet coefficients 


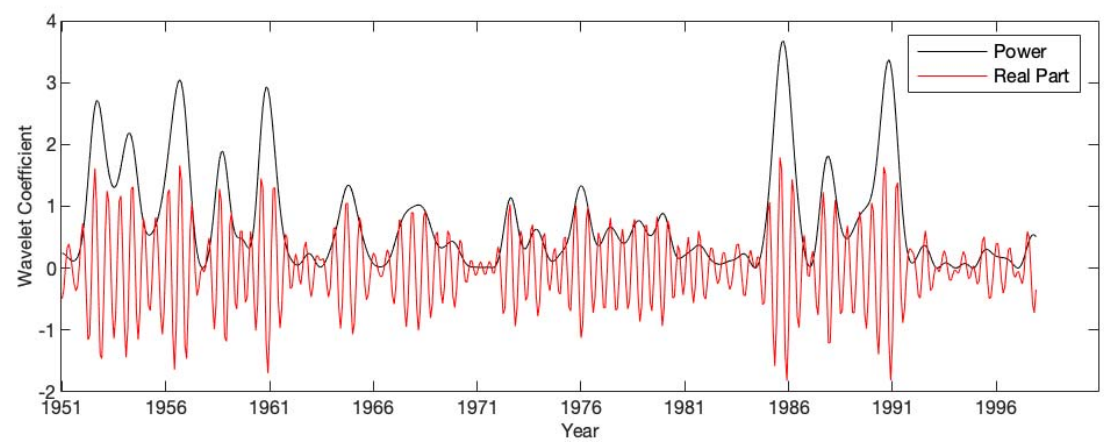

Figure 8. PRCP Real part value and wavelet power value of main period wavelet coefficients of 12-month period

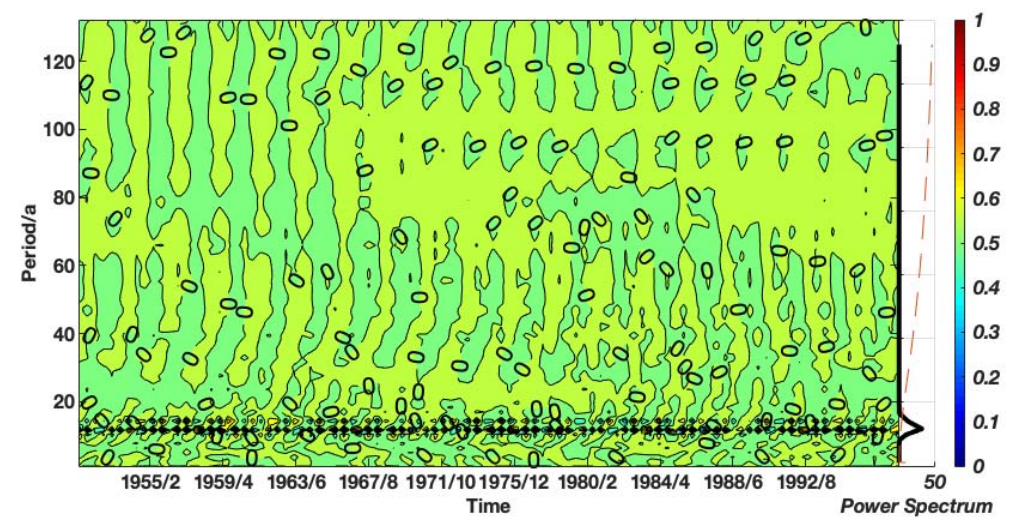

Figure 9. TAVG Real part contour map of Morlet wavelet coefficients

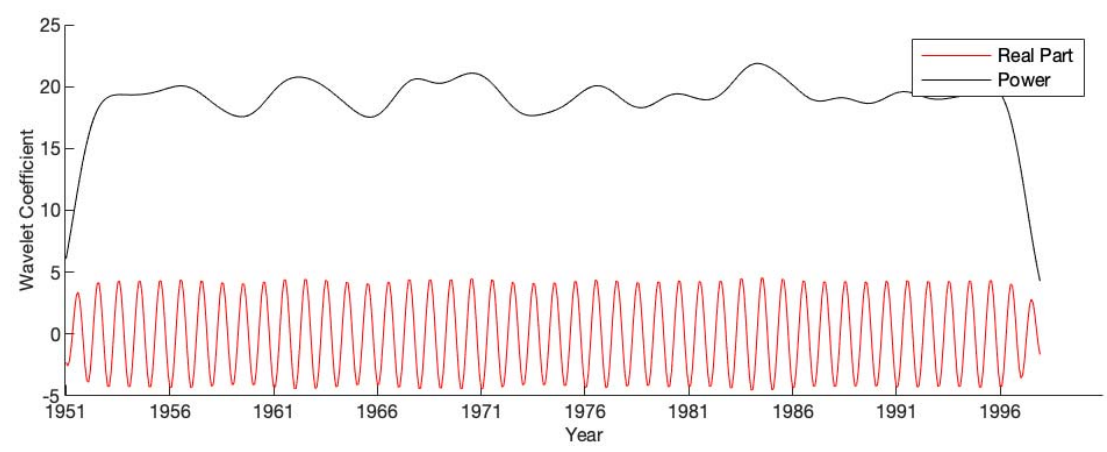

Figure 10. TAVG Real part value and wavelet power value of main period wavelet coefficients of 12-month period 


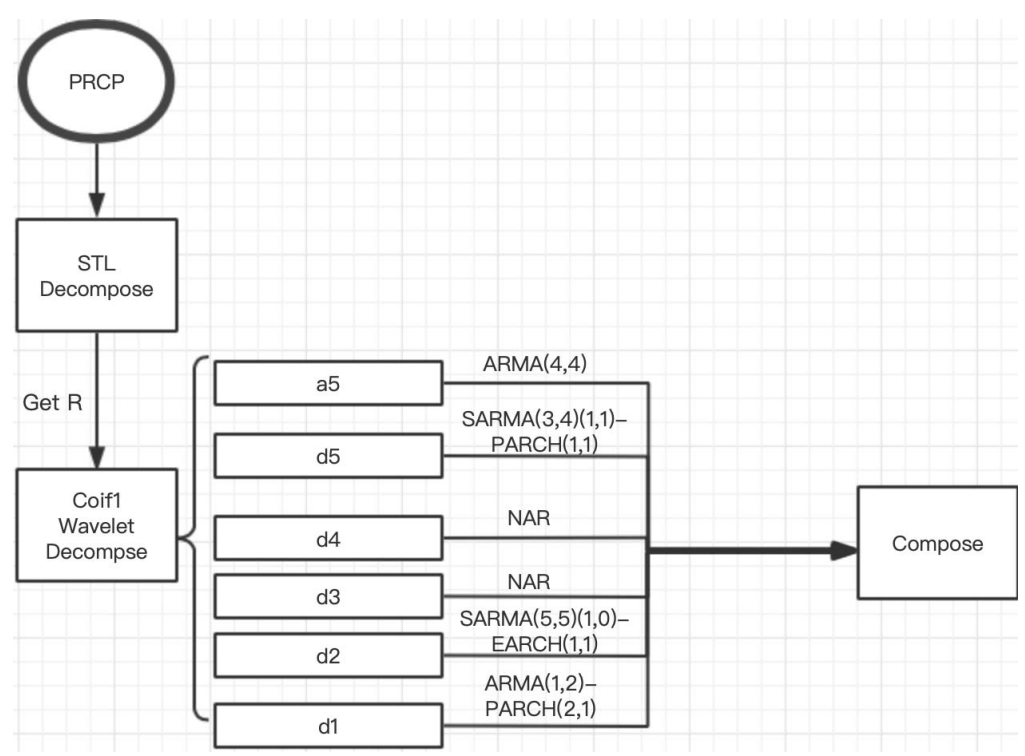

Figure 11. Flow chart of research process
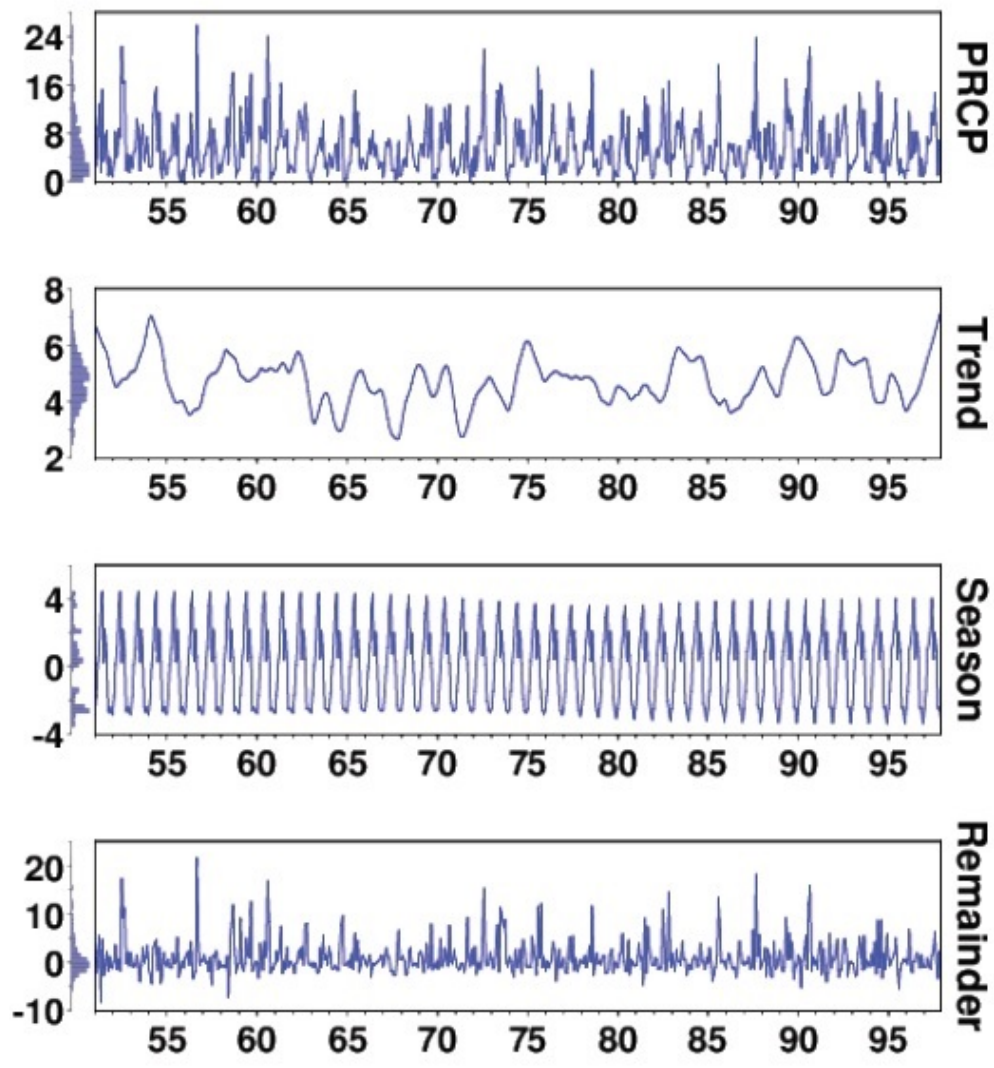

Figure 12. STL decomposition on time series data 

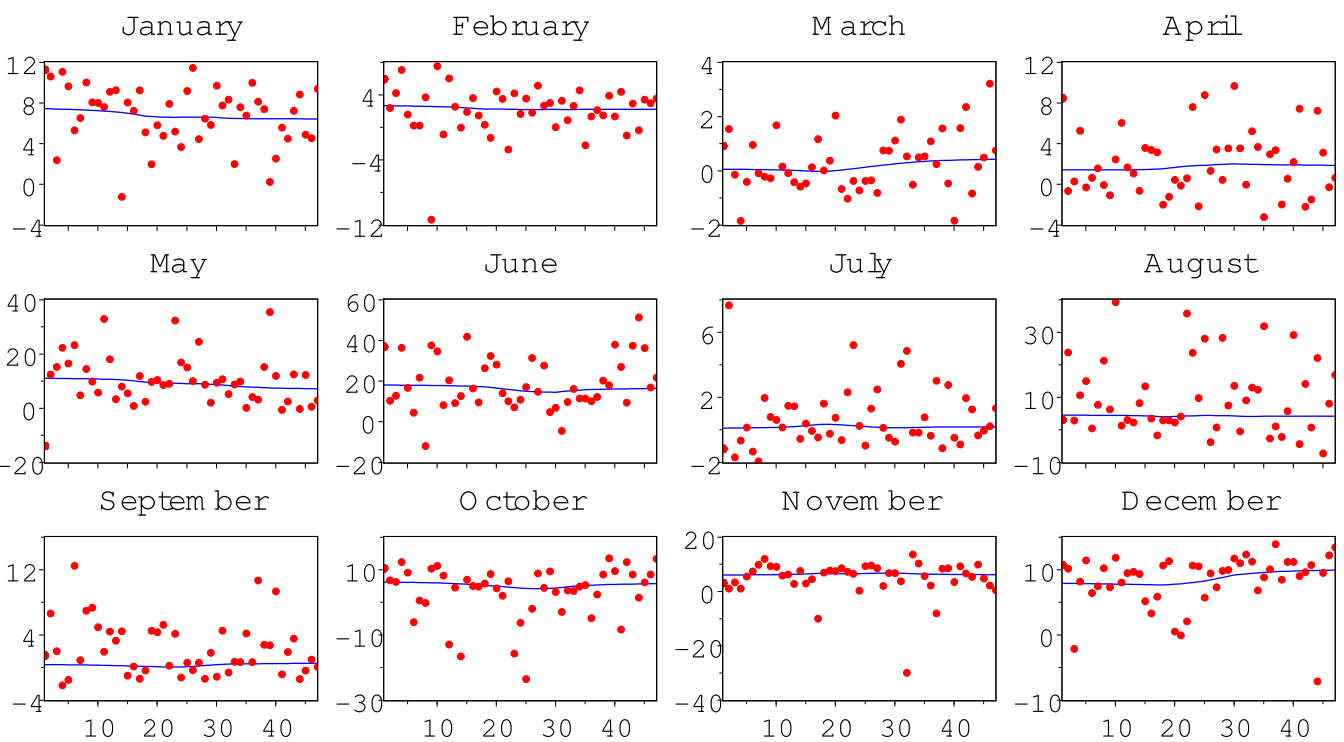

August

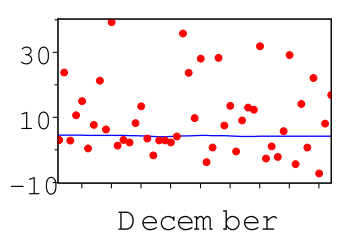

Figure 13. Seasonal Diagnostics panels by STL Decomposition

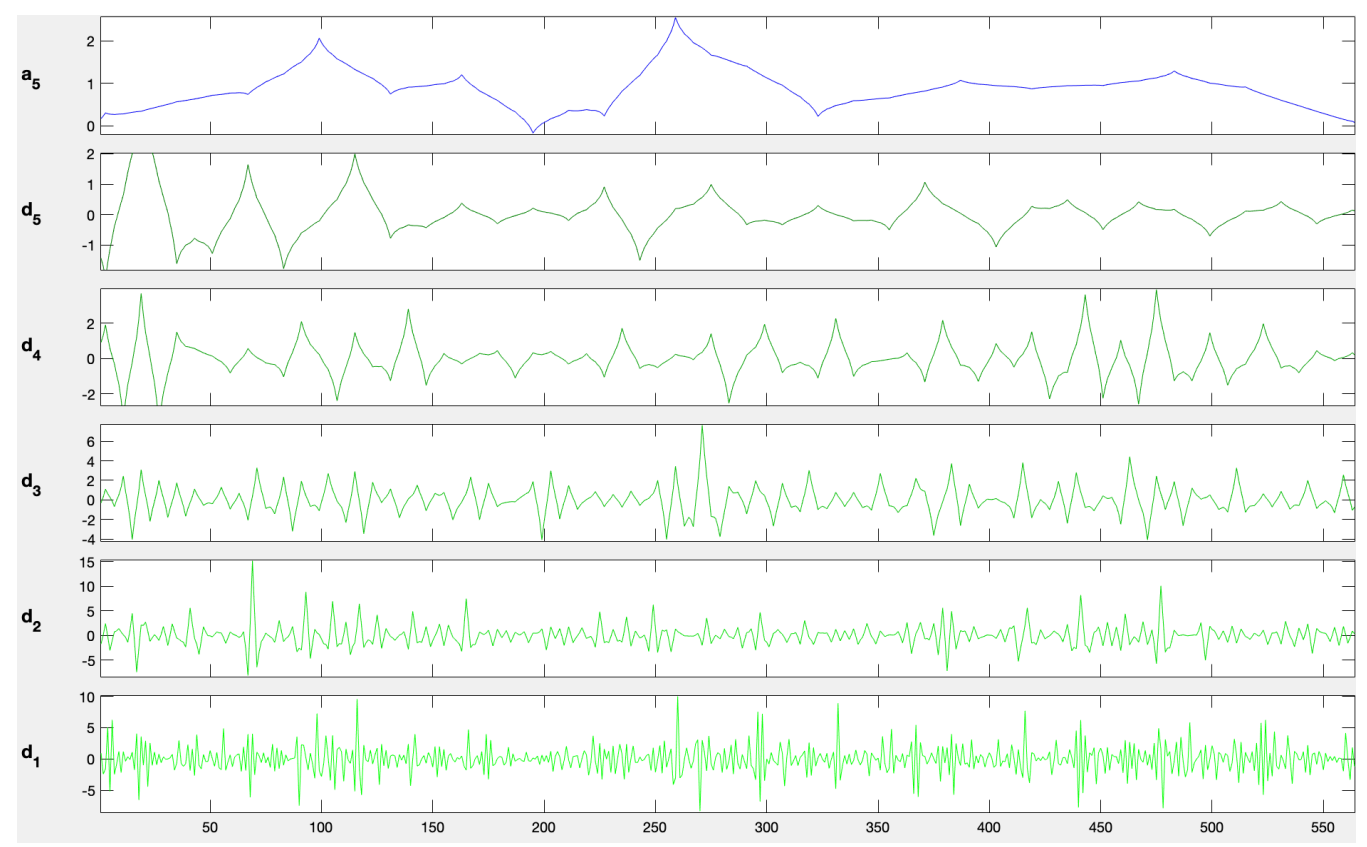

Figure 14. Coif1 wavelet decomposition Of PRCP 


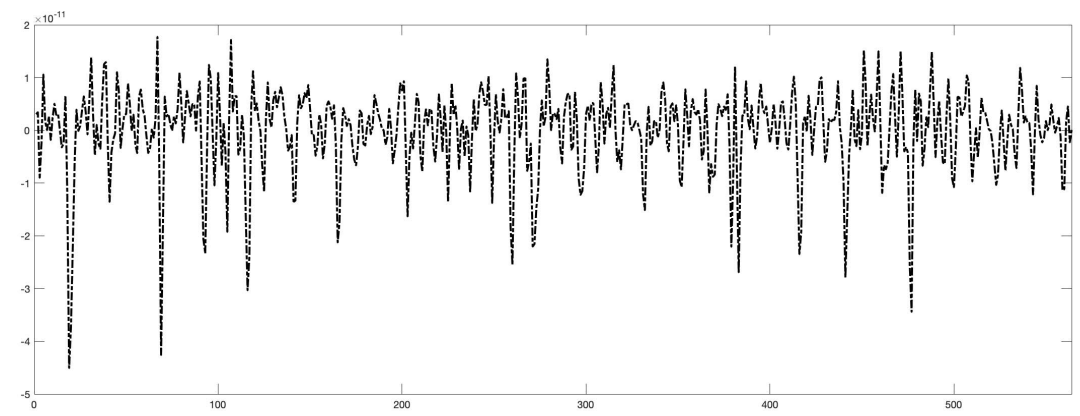

Figure 15. Residuals of reconstruction by coifwavelet decomposition

\section{Copyrights}

Copyright for this article is retained by the author(s), with first publication rights granted to the journal.

This is an open-access article distributed under the terms and conditions of the Creative Commons Attribution license (http://creativecommons.org/licenses/by/4.0/). 
Sample: 1951M01 1997M12

Included observations: 564

\begin{tabular}{|c|c|c|c|c|c|c|}
\hline Autocorrelation & Partial Correlation & & $A C$ & PAC & Q-Stat & Prob \\
\hline 미 & 다 & 1 & -0.095 & -0.095 & 5.1364 & 0.023 \\
\hline $1 \square$ & 挐 & 2 & 0.213 & 0.206 & 31.025 & 0.000 \\
\hline$\sqrt{1}$ & $\sqrt{1}$ & 3 & -0.115 & -0.084 & 38.570 & 0.000 \\
\hline 1ן & 11 & 4 & 0.042 & -0.017 & 39.559 & 0.000 \\
\hline di & di & 5 & -0.122 & -0.085 & 48.097 & 0.000 \\
\hline | | 1 & 11 & 6 & 0.038 & 0.012 & 48.933 & 0.000 \\
\hline - 1 & t! & 7 & -0.121 & -0.081 & 57.313 & 0.000 \\
\hline 10 & 1 & 8 & 0.080 & 0.044 & 60.953 & 0.000 \\
\hline 다. & प1 & 9 & -0.114 & -0.069 & 68.393 & 0.000 \\
\hline ! & । & 10 & 0.206 & 0.161 & 92.856 & 0.000 \\
\hline 디 & 1 1 & 11 & -0.108 & -0.050 & 99.588 & 0.000 \\
\hline 叶 & 11 & 12 & 0.190 & 0.099 & 120.46 & 0.000 \\
\hline 니 & 1 & 13 & -0.114 & -0.046 & 128.02 & 0.000 \\
\hline 10 & 11 & 14 & 0.094 & 0.013 & 133.14 & 0.000 \\
\hline प1 & 14 & 15 & -0.117 & -0.041 & 141.10 & 0.000 \\
\hline
\end{tabular}

Figure 16. Squared Residuals Autocorrelation diagram

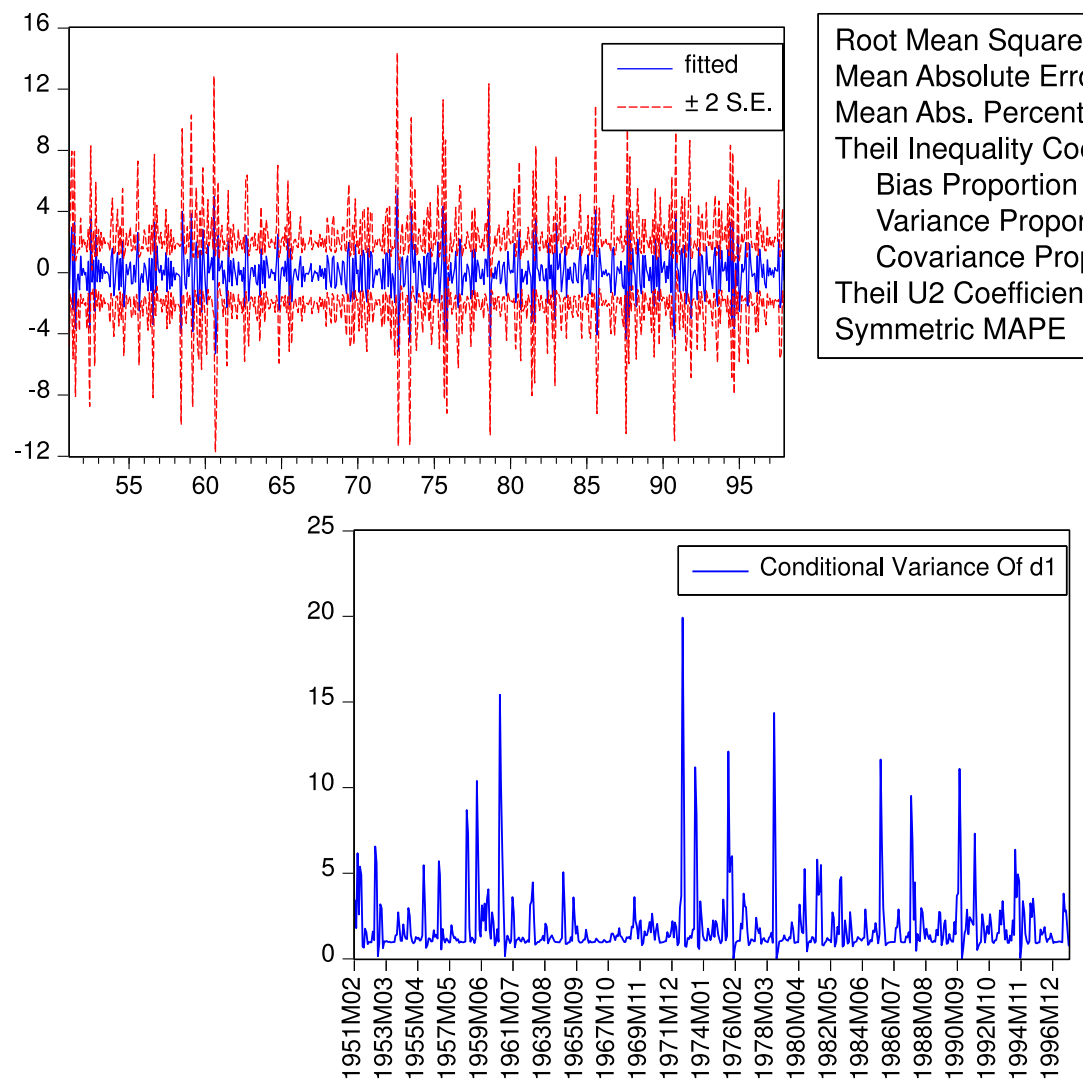

Figure 17. fitted graph with standard errors and conditional variance graph 


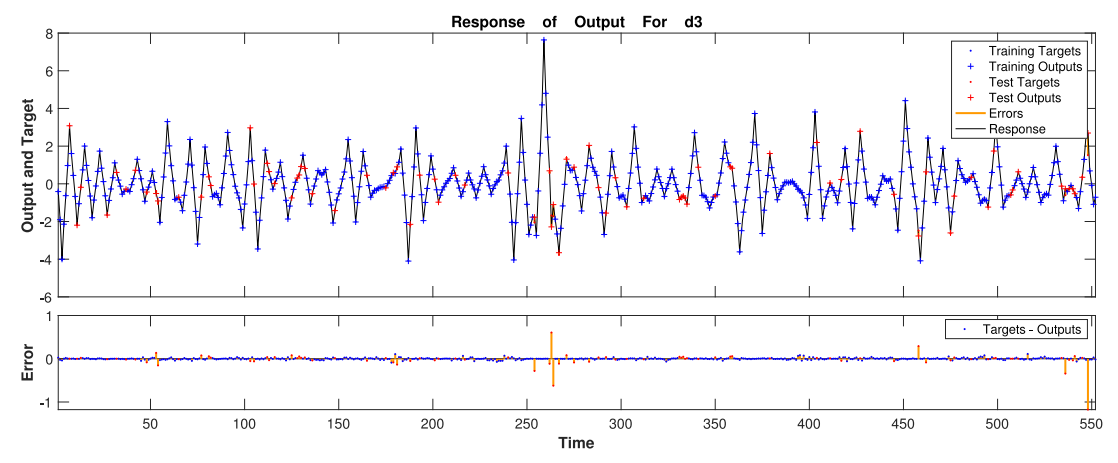

Figure 18. Response of output for $\mathrm{d} 3$ model

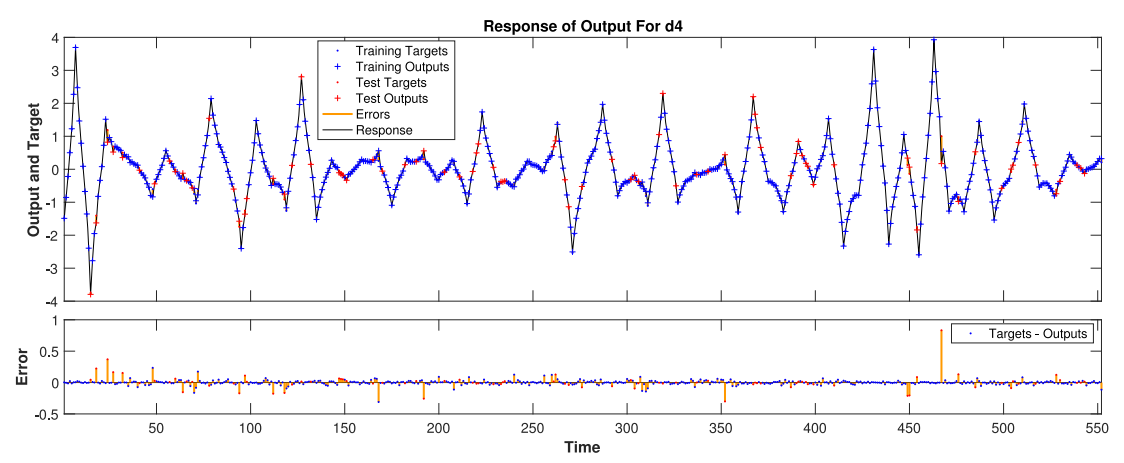

Figure 19. Response of output for d4 model

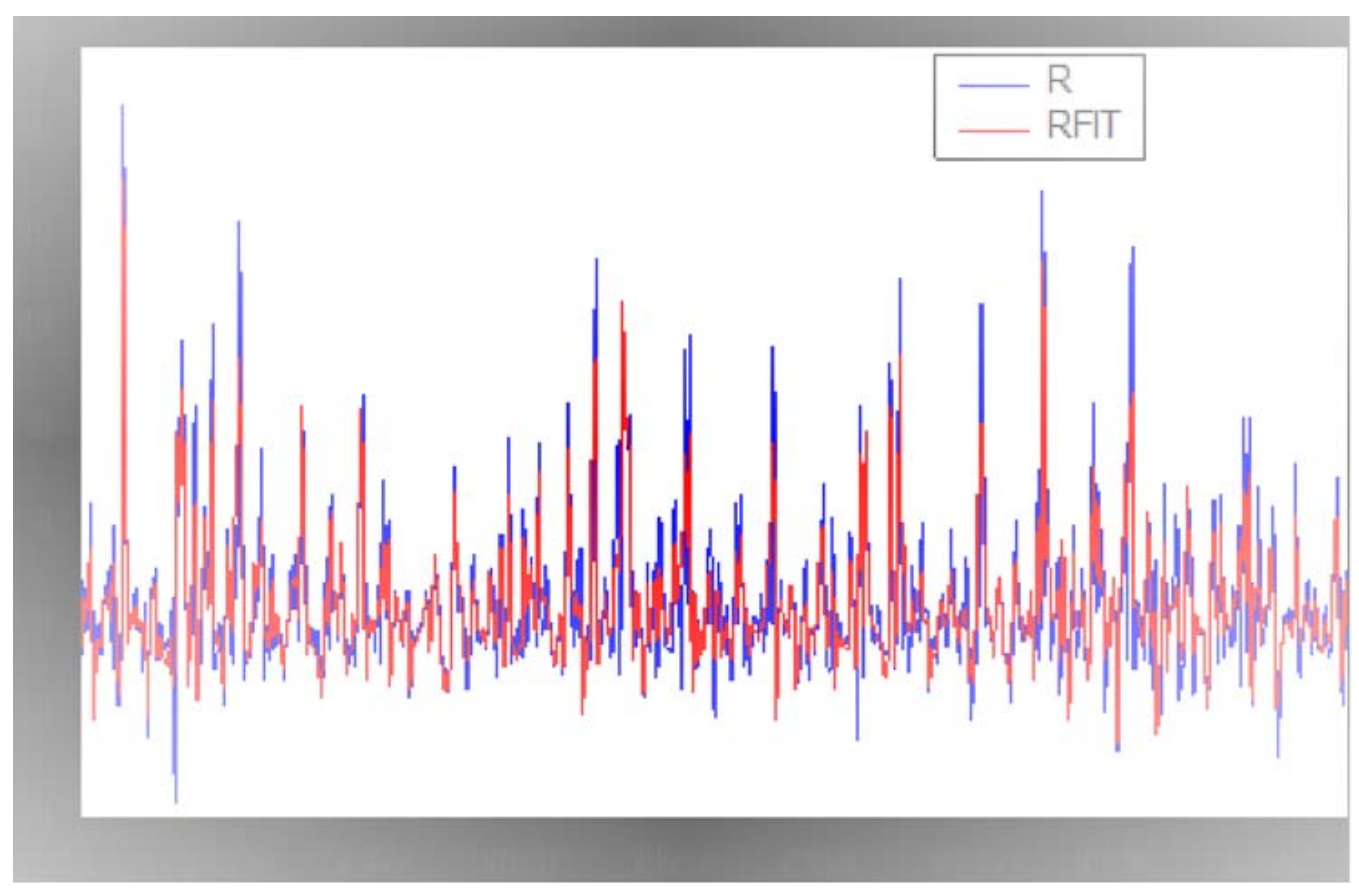

Figure 20. The $R_{t}$ and $\hat{R}_{t}$ 


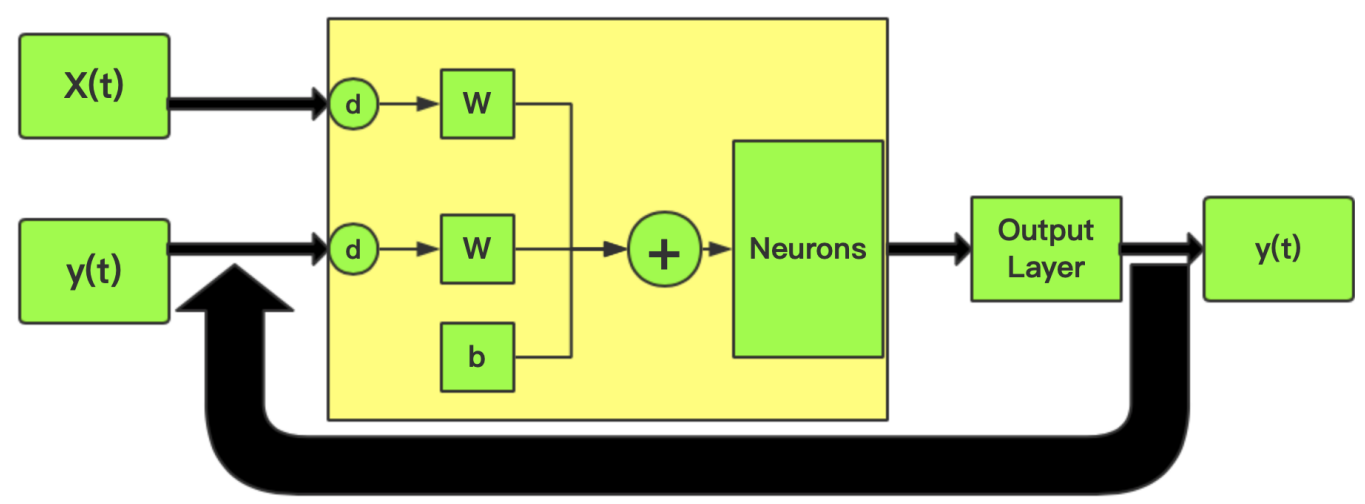

Figure 21. The Nonlinear Autoregressive Exogenous (NARX) Neural Network structure

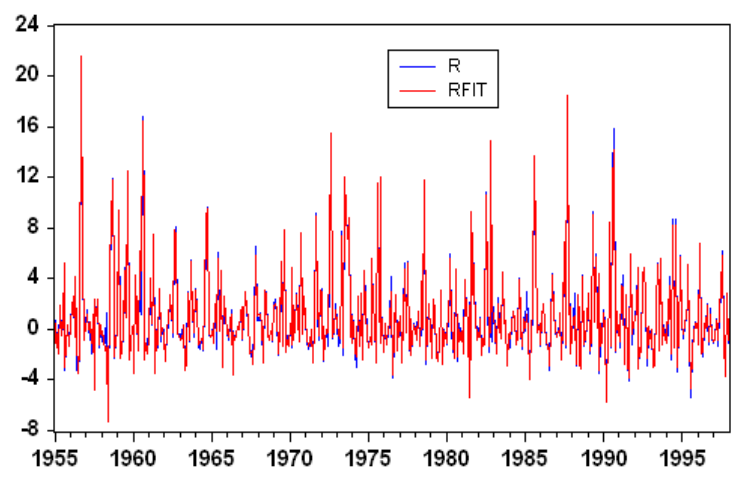

Figure 22. The updated $R_{t}$ and $\hat{R}_{t}$ from the NARX model

\begin{tabular}{|c|c|c|c|c|c|c|}
\hline Autocorrelation & Partial Correlation & & $A C$ & PAC & Q-Stat & Prob \\
\hline 111 & 111 & 1 & -0.022 & -0.022 & 0.2770 & 0.599 \\
\hline 111 & 11 & 2 & 0.022 & 0.022 & 0.5604 & 0.756 \\
\hline וך & 1) & 3 & 0.038 & 0.039 & 1.3854 & 0.709 \\
\hline 111 & 11 & 4 & -0.015 & -0.014 & 1.5107 & 0.825 \\
\hline וך ו & 10 & 5 & 0.064 & 0.062 & 3.8692 & 0.568 \\
\hline 4 & 4 & 6 & -0.077 & -0.075 & 7.2166 & 0.301 \\
\hline 111 & 11 & 7 & 0.018 & 0.013 & 7.3927 & 0.389 \\
\hline पें & पें & 8 & -0.109 & -0.112 & 14.167 & 0.078 \\
\hline | & | & 9 & 0.029 & 0.034 & 14.649 & 0.101 \\
\hline 回 & 叫 & 10 & -0.057 & -0.062 & 16.522 & 0.086 \\
\hline $1 \mid 1$ & 11 & 11 & -0.008 & 0.010 & 16.557 & 0.122 \\
\hline ص1 & 10 & 12 & 0.105 & 0.095 & 22.944 & 0.028 \\
\hline 11 & 11 & 13 & -0.003 & 0.023 & 22.948 & 0.042 \\
\hline 1 & di & 14 & -0.040 & -0.066 & 23.853 & 0.048 \\
\hline 11 & 111 & 15 & 0.016 & 0.022 & 24.008 & 0.065 \\
\hline
\end{tabular}

Figure 23. Residuals Autocorrelation diagram For a5 


\begin{tabular}{|c|c|c|c|c|c|c|}
\hline Autocorrelation & Partial Correlation & & $\mathrm{AC}$ & $\mathrm{PAC}$ & Q-Stat & Prob \\
\hline $1 \mid 1$ & $1 \mid 1$ & 1 & -0.004 & -0.004 & 0.0073 & 0.932 \\
\hline 1 & 1 & 2 & 0.020 & 0.020 & 0.2430 & 0.886 \\
\hline 11 & \begin{tabular}{l|l}
1 & 1
\end{tabular} & 3 & 0.003 & 0.003 & 0.2479 & 0.970 \\
\hline 12 & 1 & 4 & 0.092 & 0.092 & 5.1089 & 0.276 \\
\hline 11 & 1 & 5 & 0.002 & 0.003 & 5.1117 & 0.402 \\
\hline 1 & 1 & 6 & 0.091 & 0.088 & 9.8357 & 0.132 \\
\hline 11 & 11 & 7 & 0.002 & 0.002 & 9.8388 & 0.198 \\
\hline 11 & 11 1 & 8 & -0.018 & -0.029 & 10.020 & 0.264 \\
\hline $1 / 1$ & $1 / 1$ & 9 & 0.007 & 0.006 & 10.051 & 0.346 \\
\hline '1 & '1 & 10 & -0.082 & -0.100 & 13.971 & 0.174 \\
\hline $1 / 1$ & 1 & 11 & 0.011 & 0.009 & 14.037 & 0.231 \\
\hline 1 & 1 & 12 & -0.028 & -0.031 & 14.503 & 0.270 \\
\hline 11 & $1 / 1$ & 13 & 0.008 & 0.006 & 14.536 & 0.337 \\
\hline ין 1י & יקי & 14 & 0.037 & 0.061 & 15.346 & 0.355 \\
\hline $1 / 1$ & $1 / 1$ & 15 & 0.002 & 0.000 & 15.350 & 0.427 \\
\hline
\end{tabular}

Figure 24. Residuals Autocorrelation diagram For d1

\begin{tabular}{|c|c|c|c|c|c|c|}
\hline Autocorrelation & Partial Correlation & & $\mathrm{AC}$ & $\mathrm{PAC}$ & Q-Stat & Prob \\
\hline ין ו & ין ו & 1 & 0.028 & 0.028 & 0.4357 & 0.509 \\
\hline tr & 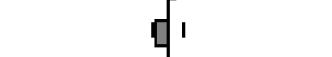 & 2 & -0.069 & -0.070 & 3.1265 & 0.209 \\
\hline ין ו & יןו & 3 & 0.035 & 0.039 & 3.8068 & 0.283 \\
\hline י & 1 & 4 & -0.052 & -0.059 & 5.3445 & 0.254 \\
\hline 13 & 1 & 5 & 0.077 & 0.087 & 8.7398 & 0.120 \\
\hline 니 & - 1 & 6 & -0.138 & -0.156 & 19.628 & 0.003 \\
\hline ינן & p & 7 & 0.044 & 0.078 & 20.752 & 0.004 \\
\hline 1 & $\sqrt{1}$ & 8 & -0.004 & -0.047 & 20.760 & 0.008 \\
\hline 11 & ין ו & 9 & -0.003 & 0.036 & 20.767 & 0.014 \\
\hline 1 & 1 & 10 & 0.009 & -0.033 & 20.809 & 0.022 \\
\hline 11 & ין י & 11 & -0.005 & 0.039 & 20.821 & 0.035 \\
\hline ים & 1 & 12 & -0.050 & -0.098 & 22.248 & 0.035 \\
\hline 11 & ין י & 13 & -0.006 & 0.037 & 22.269 & 0.051 \\
\hline 1 & ישי & 14 & 0.006 & -0.031 & 22.290 & 0.073 \\
\hline 1 & יקי & 15 & -0.003 & 0.026 & 22.293 & 0.100 \\
\hline
\end{tabular}

Figure 25. Residuals Autocorrelation diagram For d2 


\begin{tabular}{|c|c|c|c|c|c|c|}
\hline Autocorrelation & Partial Correlation & & $\mathrm{AC}$ & $\mathrm{PAC}$ & Q-Stat & Prob \\
\hline $1 \mid 1$ & $1 \mid 1$ & 1 & 0.017 & 0.017 & 0.1593 & 0.690 \\
\hline 1 & 1 & 2 & 0.008 & 0.008 & 0.1962 & 0.907 \\
\hline 1 & 11 & 3 & -0.005 & -0.005 & 0.2105 & 0.976 \\
\hline 1 & 1 & 4 & 0.010 & 0.010 & 0.2652 & 0.992 \\
\hline יוגי & ו 1י & 5 & -0.040 & -0.040 & 1.1450 & 0.950 \\
\hline 111 & 11 & 6 & -0.014 & -0.013 & 1.2489 & 0.974 \\
\hline 1 & 1 & 7 & -0.001 & 0.000 & 1.2492 & 0.990 \\
\hline 1 & 11 & 8 & -0.001 & -0.001 & 1.2494 & 0.996 \\
\hline 11 & 11 & 9 & -0.007 & -0.006 & 1.2737 & 0.999 \\
\hline 11 & 1 & 10 & -0.011 & -0.012 & 1.3355 & 0.999 \\
\hline 1 & 11 & 11 & 0.009 & 0.009 & 1.3833 & 1.000 \\
\hline $1 / 1$ & $1 / 1$ & 12 & 0.014 & 0.014 & 1.4959 & 1.000 \\
\hline 11 & 1 & 13 & -0.013 & -0.013 & 1.5864 & 1.000 \\
\hline 1 & 1 & 14 & 0.004 & 0.004 & 1.5945 & 1.000 \\
\hline $1 \mid 1$ & $1 \mid$ & 15 & 0.021 & 0.020 & 1.8344 & 1.000 \\
\hline
\end{tabular}

Figure 26. Residuals Autocorrelation diagram For d3

\begin{tabular}{|c|c|c|c|c|c|c|}
\hline Autocorrelation & Partial Correlation & & $A C$ & PAC & Q-Stat & Prob \\
\hline 11 & I|1 & 1 & -0.025 & -0.025 & 0.3424 & 0.558 \\
\hline 11 & 11 & 2 & -0.002 & -0.002 & 0.3437 & 0.842 \\
\hline $1 \mid 1$ & $1 \mid 1$ & 3 & 0.003 & 0.003 & 0.3474 & 0.951 \\
\hline 111 & 11 & 4 & 0.022 & 0.022 & 0.6003 & 0.963 \\
\hline 11 & 11 & 5 & -0.023 & -0.021 & 0.8790 & 0.972 \\
\hline 11 & 11 & 6 & -0.004 & -0.005 & 0.8880 & 0.990 \\
\hline 1 & 10 & 7 & 0.046 & 0.045 & 2.0276 & 0.958 \\
\hline पi & ப் & 8 & -0.100 & -0.098 & 7.5068 & 0.483 \\
\hline 11 & 11 & 9 & 0.014 & 0.011 & 7.6116 & 0.574 \\
\hline וp & ו & 10 & 0.028 & 0.028 & 8.0304 & 0.626 \\
\hline $1 \mid 1$ & 11 & 11 & 0.011 & 0.011 & 8.1017 & 0.704 \\
\hline 대| & IDी 1 & 12 & -0.049 & -0.043 & 9.4431 & 0.665 \\
\hline 10 & 10 & 13 & 0.100 & 0.095 & 14.977 & 0.309 \\
\hline 11 & 11 & 14 & 0.004 & 0.004 & 14.985 & 0.379 \\
\hline IDI & ID| & 15 & -0.041 & -0.033 & 15.934 & 0.386 \\
\hline
\end{tabular}

Figure 27. Residuals Autocorrelation diagram For d4 


\begin{tabular}{|c|c|c|c|c|c|c|}
\hline Autocorrelation & Partial Correlation & & $A C$ & PAC & Q-Stat & Prob \\
\hline $1 / 1$ & $1 / 1$ & 1 & 0.005 & 0.005 & 0.0115 & 0.914 \\
\hline וp & וp & 2 & 0.025 & 0.025 & 0.3411 & 0.843 \\
\hline 111 & 11 & 3 & 0.014 & 0.014 & 0.4449 & 0.931 \\
\hline 10 & 17 & 4 & 0.083 & 0.082 & 4.0287 & 0.402 \\
\hline di & di & 5 & -0.068 & -0.070 & 6.4498 & 0.265 \\
\hline $1 口$ & 1口 & 6 & 0.130 & 0.128 & 15.257 & 0.018 \\
\hline IDI & 14 & 7 & -0.028 & -0.031 & 15.654 & 0.028 \\
\hline IDI & 1 & 8 & -0.046 & -0.056 & 16.747 & 0.033 \\
\hline IDI 1 & 11 & 9 & -0.025 & -0.015 & 17.082 & 0.047 \\
\hline $1 \| 1$ & 11 & 10 & 0.018 & -0.005 & 17.246 & 0.069 \\
\hline $1 \mid 1$ & ו 1 & 11 & 0.003 & 0.029 & 17.252 & 0.101 \\
\hline ו 1 1 & 11 & 12 & 0.027 & 0.015 & 17.628 & 0.127 \\
\hline 11 & 11 & 13 & -0.011 & -0.009 & 17.697 & 0.169 \\
\hline إ引 & 10 & 14 & 0.056 & 0.066 & 19.362 & 0.152 \\
\hline 111 & 111 & 15 & 0.015 & 0.014 & 19.488 & 0.192 \\
\hline
\end{tabular}

Figure 28. Residuals Autocorrelation diagram For d5 